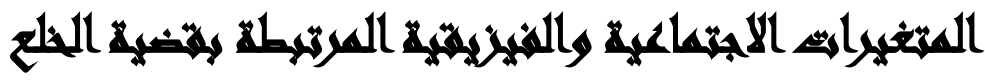

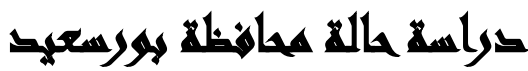

[?]

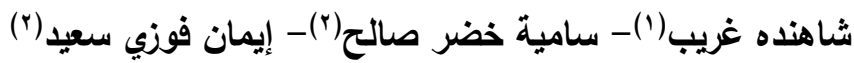

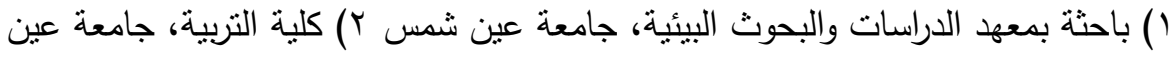

شمس بإ

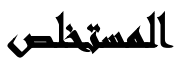

يعتبر التغير الاجتماعي من بين الظواهر الاجتماعية التي مرت وتمر بها كافة الإنة

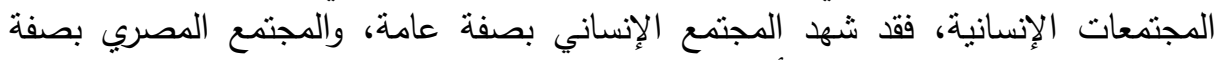

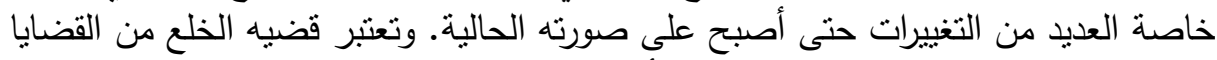

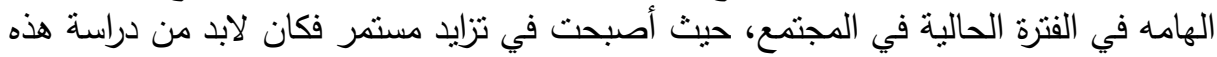

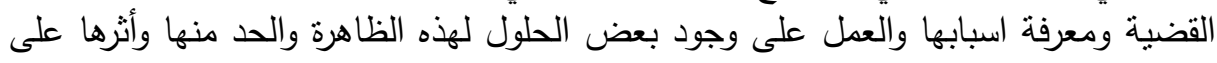

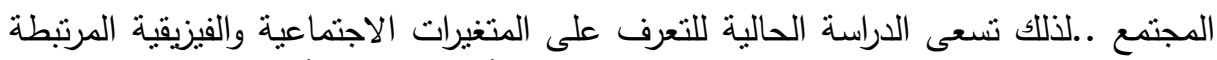

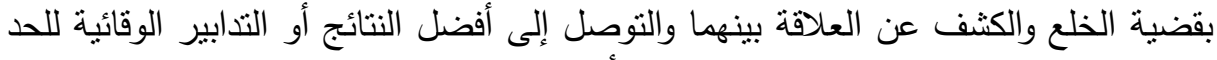

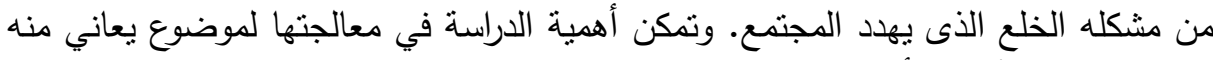

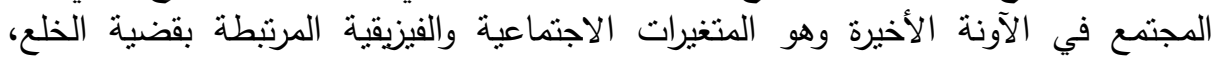

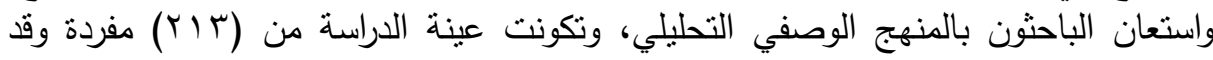

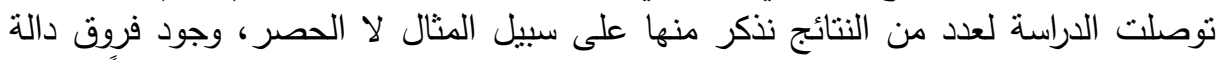

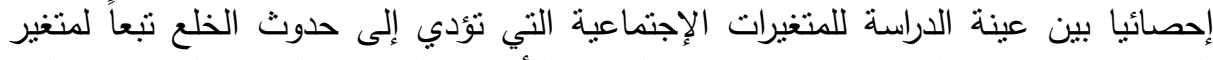

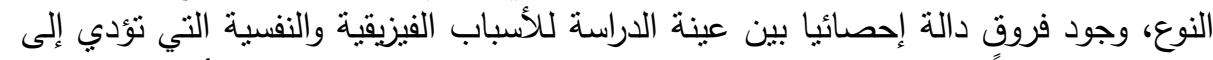

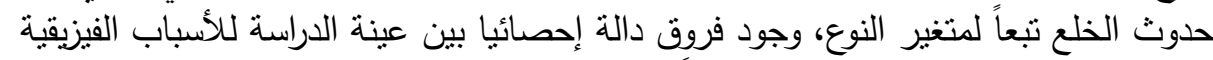

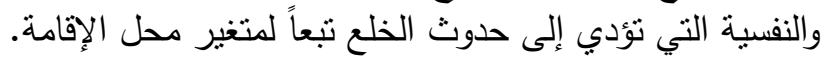
التوصيات:

• • عمل ندوات ومحاضرات في مراكز الاسرة والطفولة في تأهيل المتقدمين للزواج.

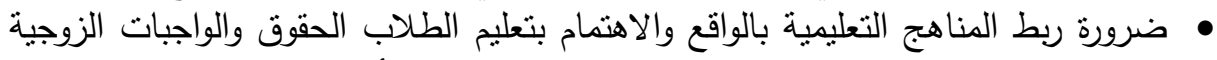

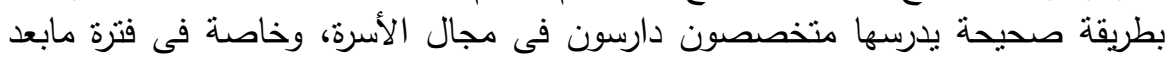
التعليم الأساسي. 
• لابد من نتشيط دور العبادة لتعليم الأزواج الحقوق والواجبات الزوجية من الكتاب والسنة النبوية الثريفة ومناشدتهم فى أن يتقوا الله فى زوجاته لتهم وأبنائهم.

\section{ه内人}

يعتبر النظام الزواجي كأحد الأنظمة الاجتماعية الموجودة في المجتمع المصري من اهم

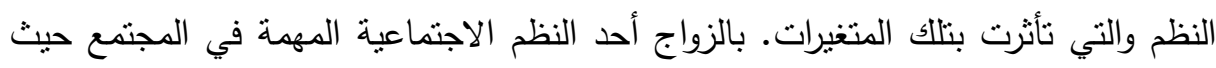

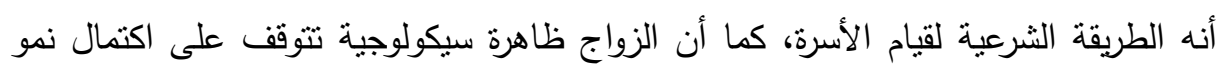
الثخصية والاستعداد للاندماج مع الأفراد، والتضحية في سبيله.

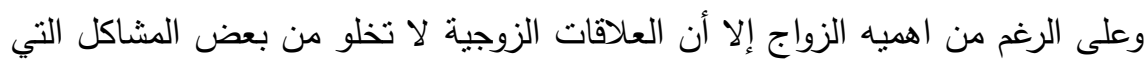

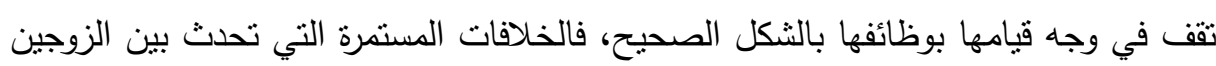

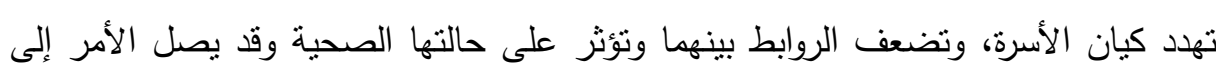

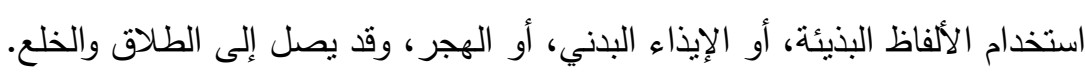

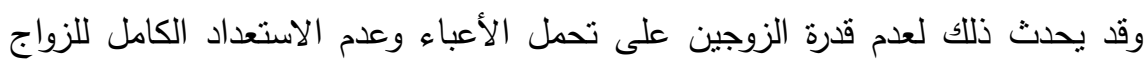
واجتماعيا واقتصاديا. وقد يتعرض الزواج لمشكلات وخاصه في المرحلة الأولى نظرا لقلة خبرة

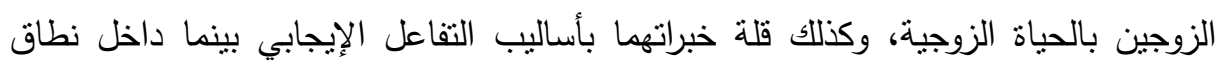

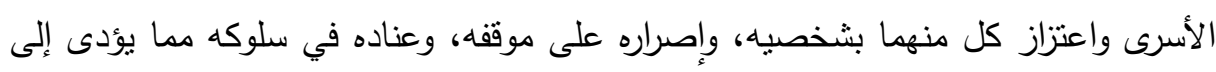

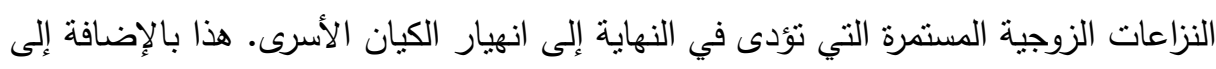

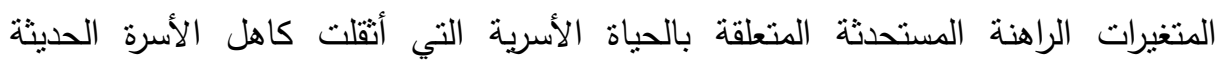

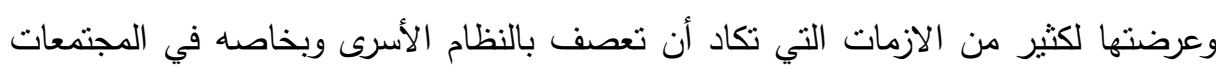
العربية.

فالحياة الزوجية لا تخلو بشكل عام خلال دورتها من بعض الصعوبات والمشكلات

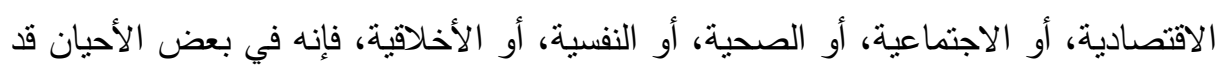

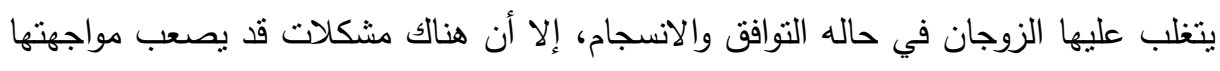

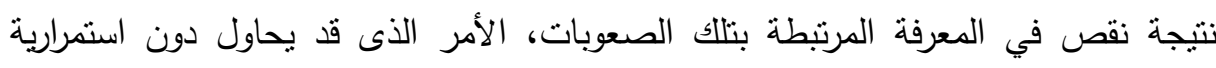
الحياة، وعند ئذ قد يلجا أحد الزوجين أوكلاهما إلى طلب الطلاق كحل افضل لهذه لهن المشكلات. 
ويعتبر الطلاق والخلع ظاهره اجتماعيه إنسانيه قديمة حديثه، لذا فإن نجاح الحياه الأسرية يتوقف على اختيار الثريك المناسب، لأنه الأساس الأول في عمليه الزواج، فنجاع إنهاح

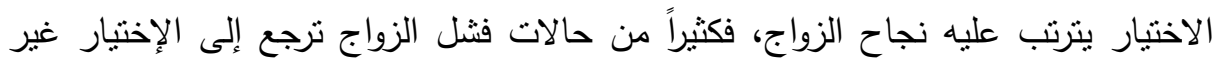

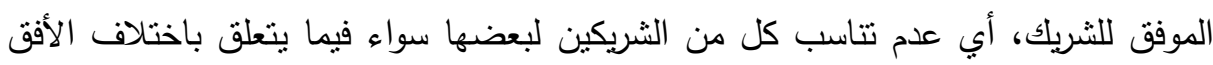

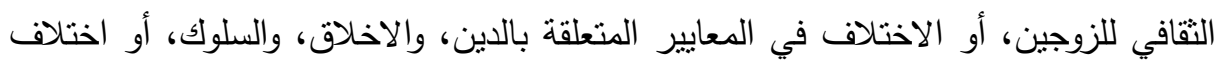
المكانة الاجتماعية والاقتصادية.

وقد يتعرض الزواج لمشكلات خاصه في مرحله الأولى نظرا لقله الخبرة الزوجين بالحياة

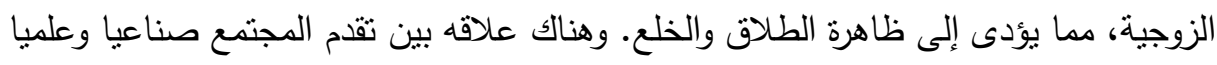
وزياده المشاكل الاجتماعية فيه، ومنها الطلاق والخلع ولهذا يعد الطلاق والخلع بصفه عامه وهنه

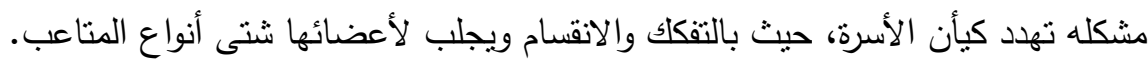

\section{هم:حلع التراسما.}

في ظل وجود ارتفاع حالات الطلاق والخلغ في الاونة الاخيرة، حيث أثنارت إحصاءات

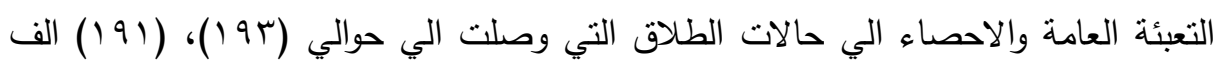

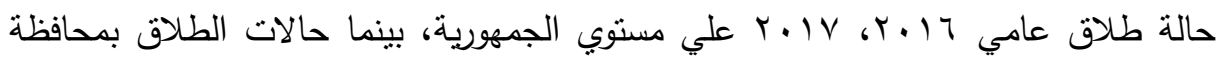

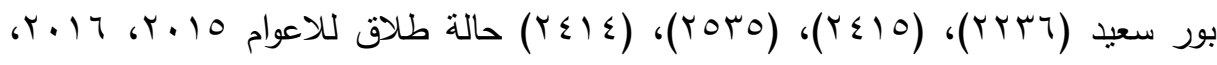

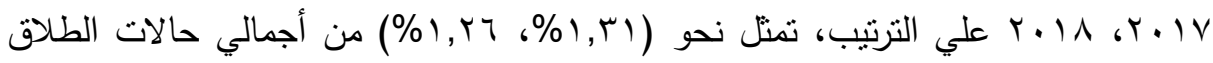

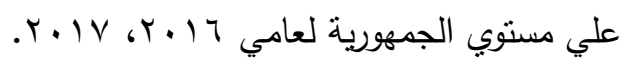

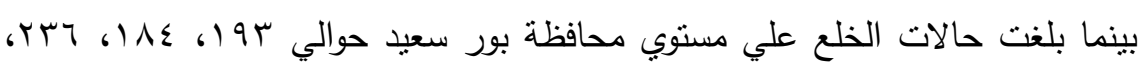

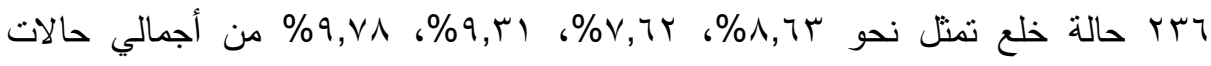

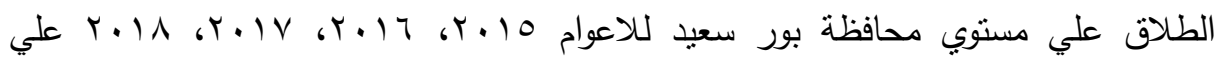

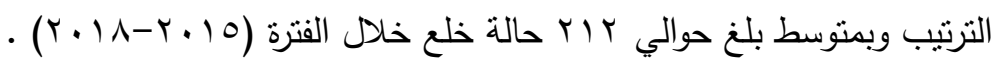
ومع ازدياد حالات الطلاق والخلع نتيجة التفكك الاسرى الناتج عن المشكلات الاسرية التي تهدد الأسرة المصرية وتتسبب في انهيار المجتمع ككل، مما يستدعى نوظيف جهود 
العلوم الاجتماعية لمواجنها. لذلك تسعى الدراسة الحالية للتعرف على المتغيرات الاجتماعية

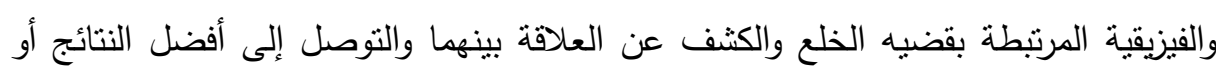
التدابير الوقائية للحد من مشكله الخلع الذى يهدد المجتمع. ولهذا أعطى للرجل حق إنهاء

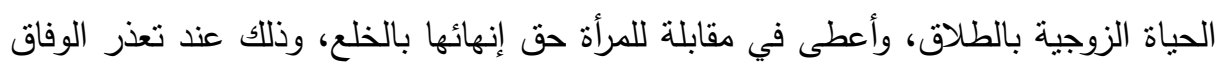

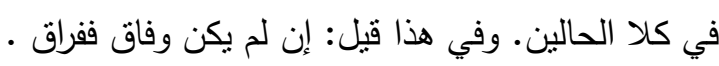

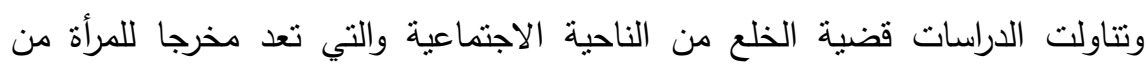

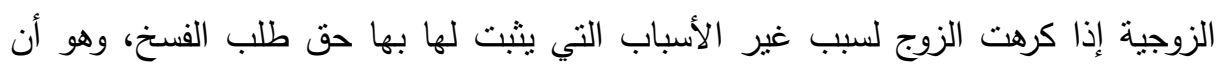

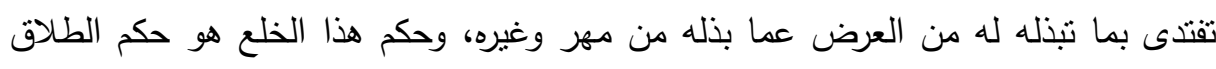

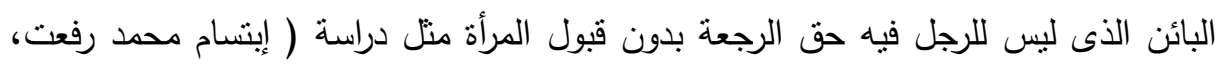

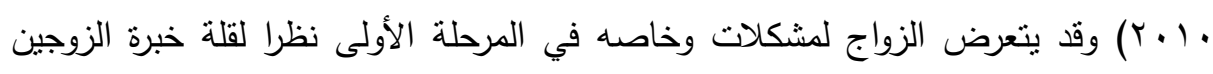

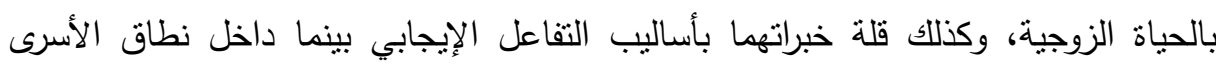

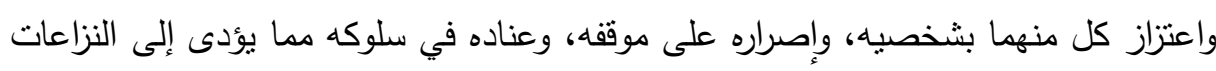

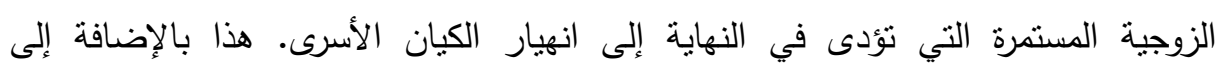

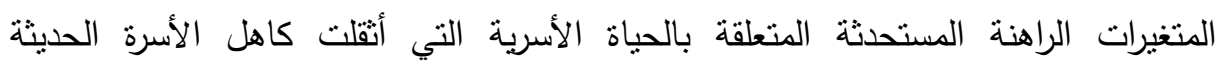

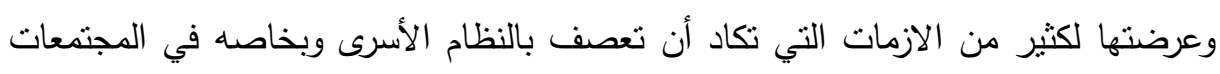
العربية . وعرضن

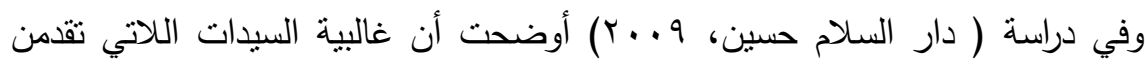

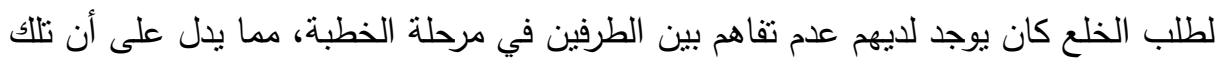

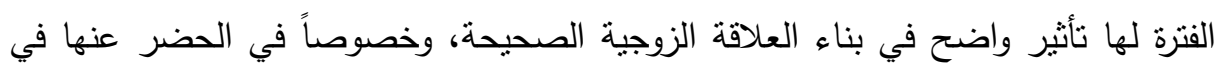
الريف، حيث تسود علاقات المباشرة في الحضر • وأن أهم أسباب طلب الزوجة للخلع يتمنل

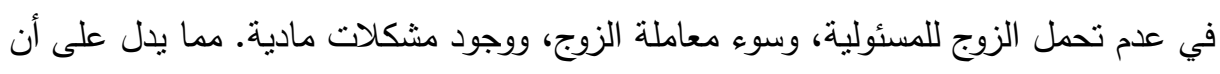

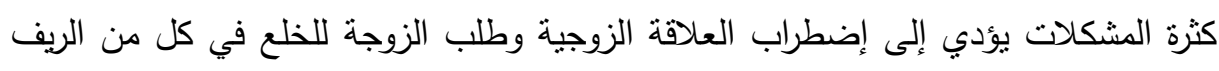

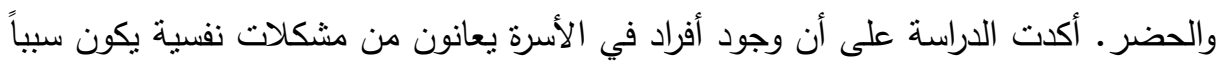
قوياً في طلب الخلع. 


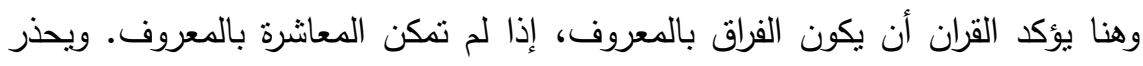

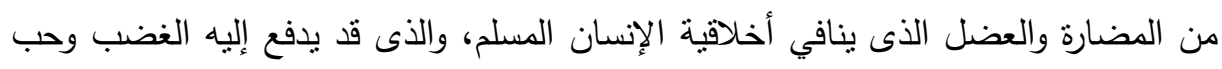

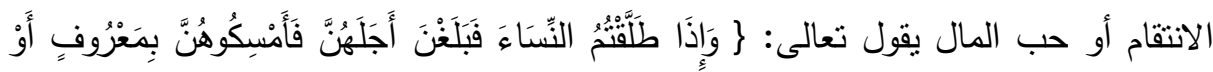

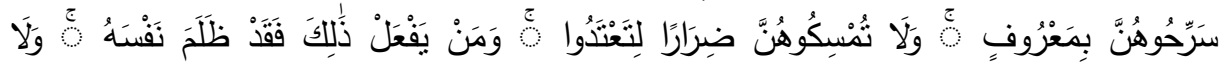

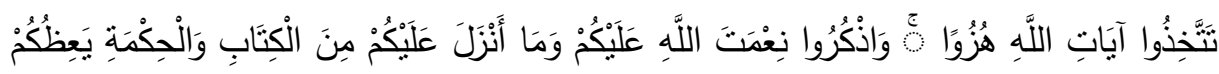

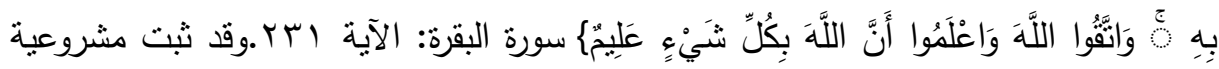

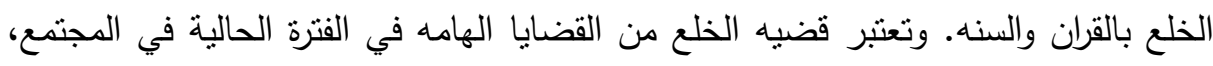

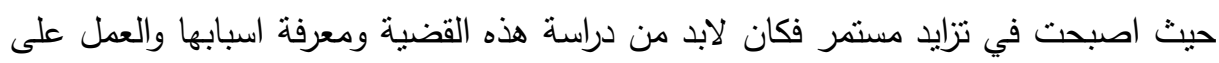

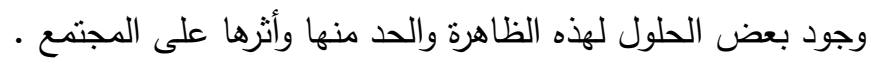
ومن هنا جاءت الدراسة للكثف والتعرف على المتغيرات الاجتماعية والفيزيقية المرتبطة بقضيه الخلع والاسباب التي تدفع المرأة لرفع دعاوى الخلع وتأثير ذلك على الأسرة والنتائج

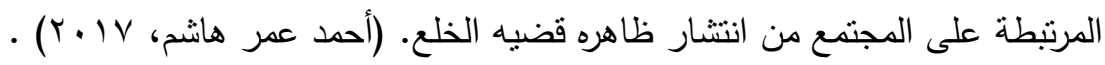

\section{تحاولائس الصوراسة}

كل دراسة لها عدة تساؤلات تسير في سياق متغيرات الدراسة وتحاول الباحثة الإجابه عن هذه التساؤلات فقد كان النساؤل الرئيسي لهذه الدراسة هو: ما العلاقة بين المتغيرات

الاجتماعية والفيزيقية المرتبطة بقضيه الخلع؟ وينبثق من هذا التساؤل الرئيسي عده تساؤلات فرعيه وهى على النحو النحو الآتي: 1- الما المقصود بقضيه الخلع من الناحية الثرعية والقانونية؟ r-ما المتغيرات الاجتماعية التي تؤدى الى قضيه الخلع؟

ץ-ما المتغيرات الفيزيقية التي تؤدى الى قضيه الخلع؟

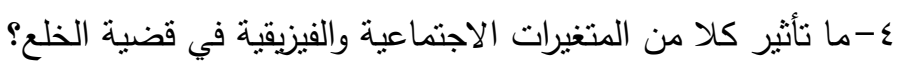




\section{أهمية القواسمة}

أ) الأهمية الاجتماعية:

1-التعرف على ظاهره قضبه الخلع في المجتمع واسبابها والعمل على الحد منها داخل

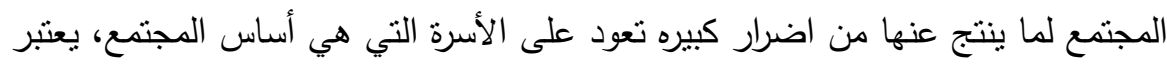

$$
\text { أن الأسرة هي نواة المجتمع. }
$$

r-الأسباب الاجتماعية التي تؤدى الى وجود المشكلات الأسرية التي تؤدى إلى الخلع بصفه خاصه أو الطلاق بصفه عامه.

ץ-الأسباب الفيزيقية التي تؤدى الى وجود المشكلات الأسرية التي تؤدى إلى الخلع بصفه خاصه او الطلاق بصفه عامه.

ع-الأسباب التي تدفع المرأة لرفع دعاوى الخلع. الزواج كمؤسسة اجتماعية ثقافيه نفسية.

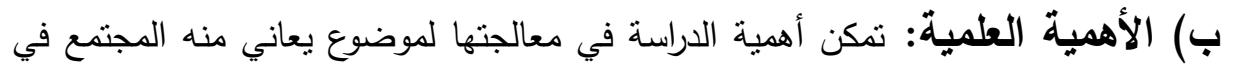
الآونة الأخيرة وهو المتغيرات الاجتماعية والفيزيقية المرتبطة بقضية الخلع ( دراسة حالة محافظة بورسعيد) ومدي انعكاس المتغيرات البيئة الفيزيقية والاجتماعية وآثارها على قضيه الإنيه الخع داخل الاسرة في المجتمع.

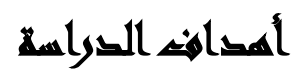

تسعى هذه الدراسة إلى تحقيق عده اهداف قد تكون سببا في إيجاد حلول لهذه القضية

$$
\text { الخلع، وتتخلص هذه الأهداف في الآتي: }
$$$$
\text { 1- التعرف على معنى الخلع شرعا وقانونا. }
$$

r-التعرف على المتغيرات الاجتماعية التي تؤدى إلى الخلع. ب-التعرف على المتغيرات الفيزيقية التي تنؤدى إلى الخلع.

ع- التعرف على حجم قضايا الخلع في المجال المكاني للاراسة.

ه-تحديد شكل العلاقة بين المتغيرات الاجتماعية والفيزيقية للخع. 1- التوصل إلى أفضل النتائج أو التدابير الوقائية للحد من قضيه الخئ الخلع. 


\section{مهاهيهر التواسمة}

تأتى أهميه ذكر المصطلحات وتعريفاتها الإجرائية من كثرة المدلولات المحتملة

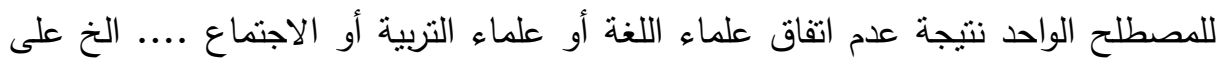

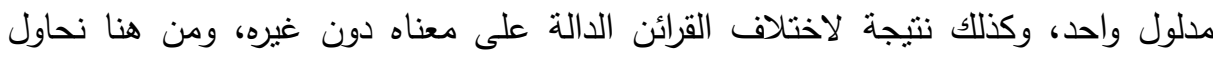

$$
\text { عرض المفاهيم الدراسة الاساسية. }
$$

( ) مفهوم المتغيرات: يرجع لفظ المتغيرات إلى كلمه التغيير الذى يشير إلى أوضاع جديدة

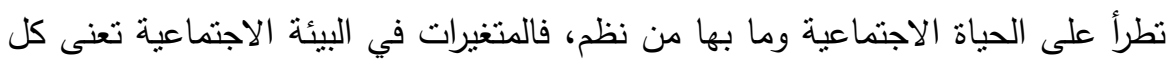

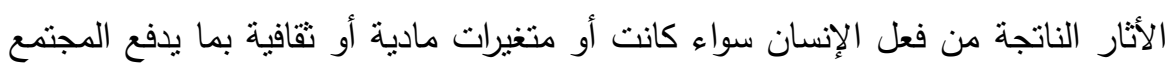
إلى الحفاظ على نظهها عن طريق ضبط سلوك أفراده.

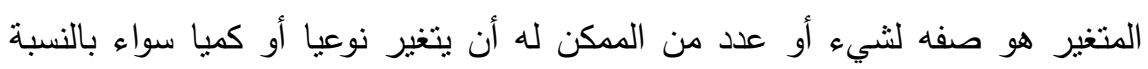

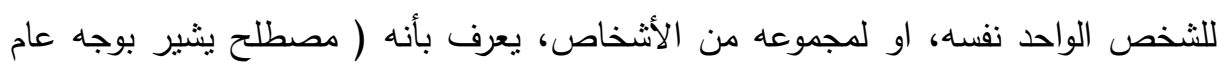
الى كميه تتغير على نحو أكثر دقه، ويكون هذا المتغير عباره على خاصية يمكن قياسها،

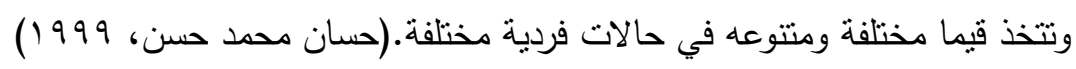

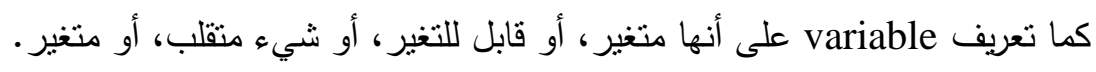
r مفهوم المتغيرات الاجتماعية: يثير مصطلح المتغيرات الاجتماعية في العلوم

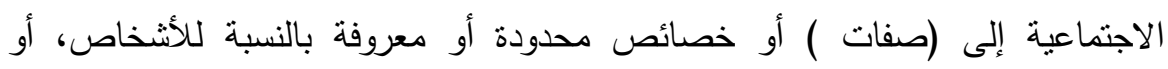
كميات، أو درجات مختلفة من واقع عينات أو مجتمعات معينه، والمتغيرات تقيس مكونات

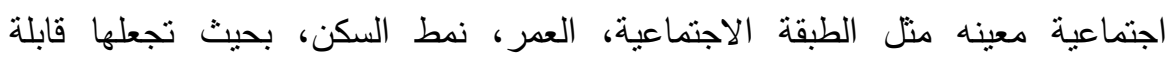
للتحليلات الكمية، أو الرقمية وهكذا فإن السمة الأساسية لأى متغير هي قدرته على إظهار

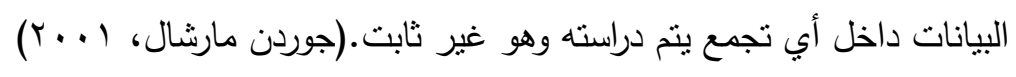

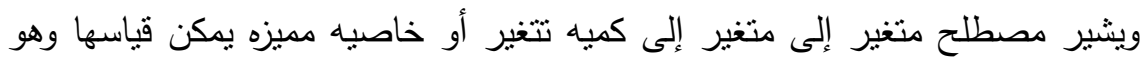
يقاس على كل ما يراد دراسته في البحث الاجتماعي. 
فالمتغير يدل على صفحه محددة تنتاول عددا من الحالات أو القيم أو الخصائص

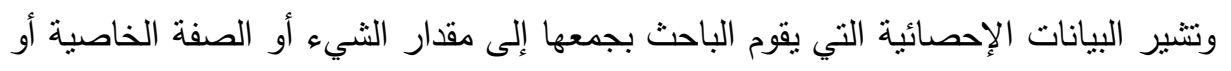

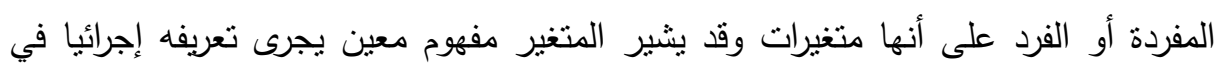

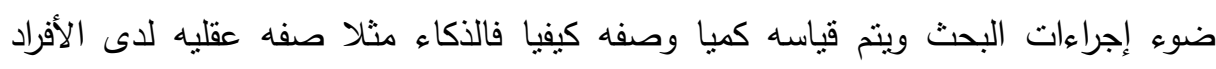

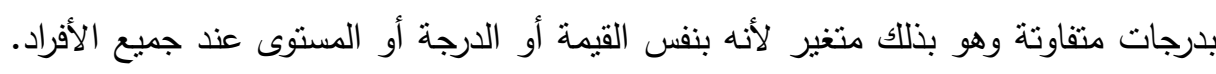
(محمد عاطف غيث، . 1999 ).

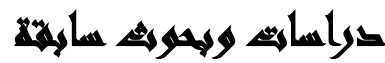

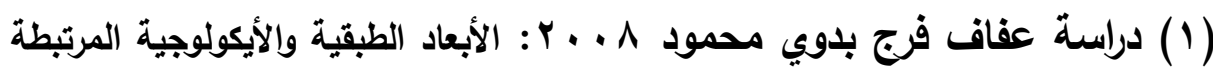

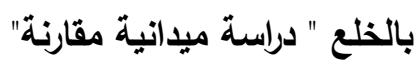

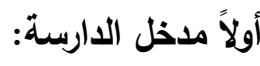

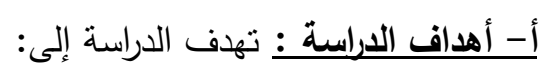

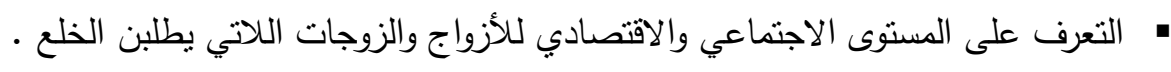

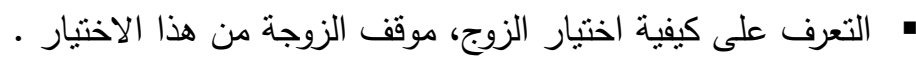

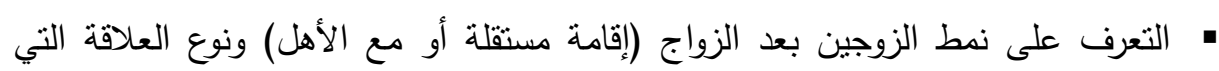
كانت تسود بين الزوجين والأهل.

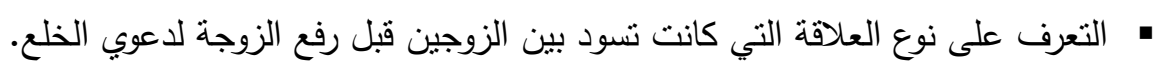

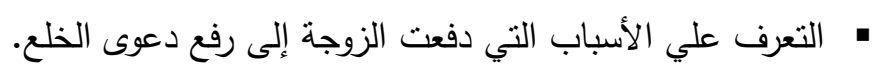

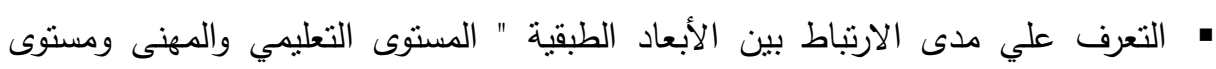

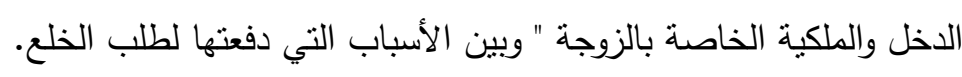

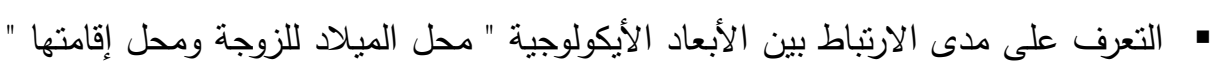

$$
\text { وبين الأسباب التي دفعتها لطلب الخلع. }
$$

ب- مثكلة الدراسة وأهميتها: تتحدد مشكلة الدراسة في محاولة التعرف على الأبعاد الطبقية

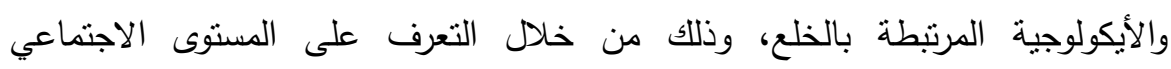

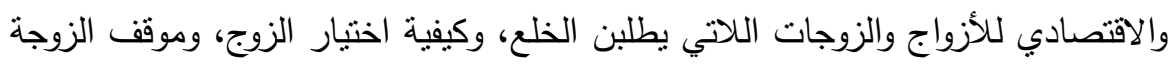


من هذا الاختيار، وعلاقة الزوجين بالأهل، ونوع العلاقة التي كانت تسود بين الزوجين

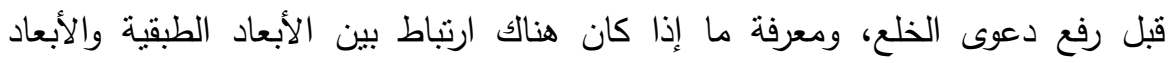

$$
\text { الأيكولوجية ولب الزوج للخلع. }
$$

\section{ج- تساؤلات الدراسية:}

• ما المستوى الاجتماعي والاقتصادي للأزواج والزوجات اللاتي بطلبن الخلع؟

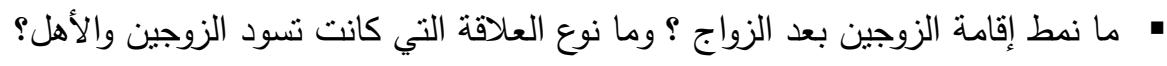

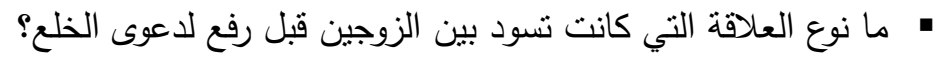

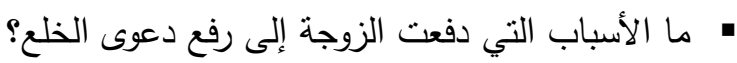

• هل توجد علاقة ارتباطية بين الأبعاد الطبقية (المستوى التعليمي والمهني ومستوى دخل

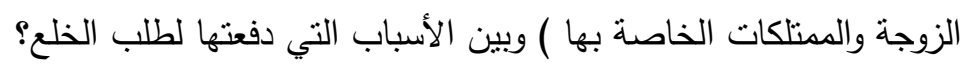

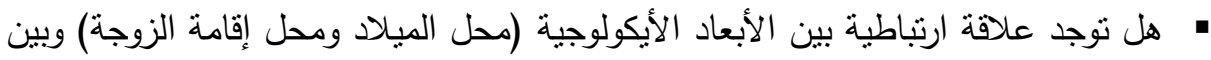

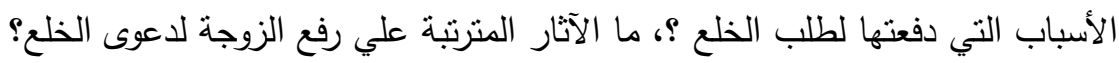

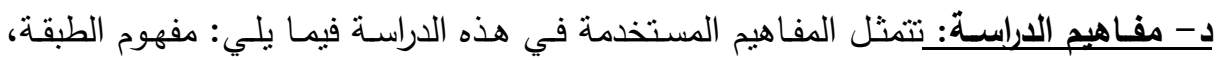
مفهوم الأيكولوجيا، مفهوم المجتمع الريفي والحضري، مفهوم الخلع .

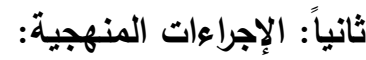
أ- نوع الدراسة: تعتبر هذه الدراسة من الدراسات الوصفية، حيث هدفت إلى جمع بيانات عن

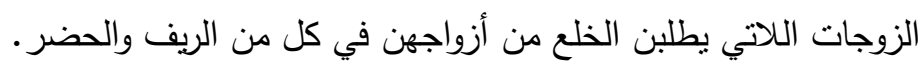

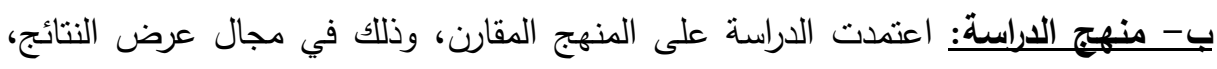
وذللك المقارنة بين الريف والحضر ، والمقارنة بين المستوى الاجتماعي والاقتصادي للأزواج

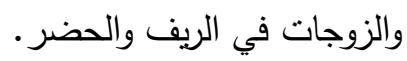

ج- عينة الدراسة: ابتعت الدراسة طريقة المسح الاجتماعي عن طريق الحصر الثامل لحالات الخلع بمكاتب تسوية المنازعات الأسرية ببعض محاكم الأسرة بمحافظتي القاهرة والثرقية، والتي مازالت تحت الدراسة خلال فترة إجراء الدراسة الميدانية. دـ أدوات الاراسة : استخدمت الدراسة المقابلة كأداة لجمع بيانات المطلوبة.

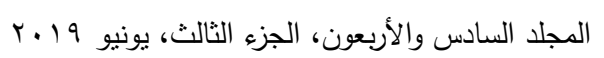




\section{(ץharon Layish 1995 ( الطلاق في الأسرة الليبية}

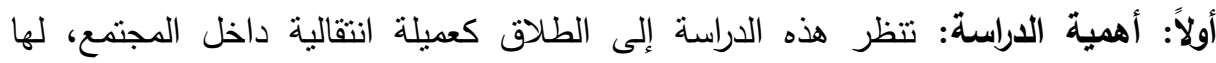

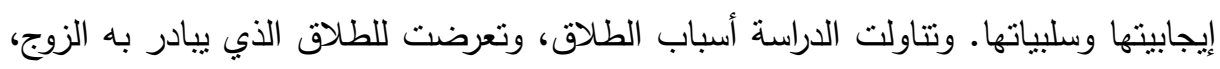

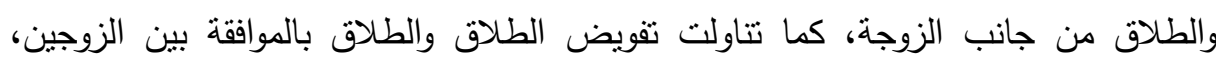

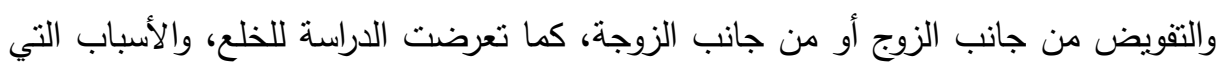

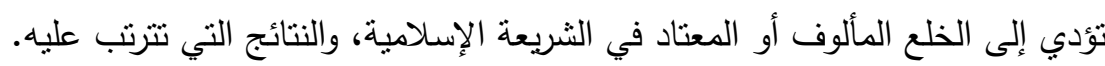

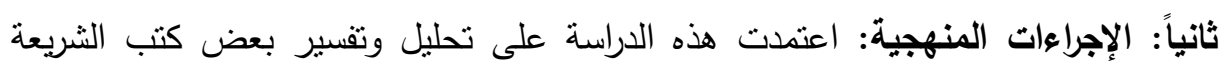

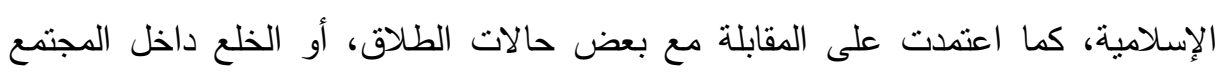
الليبي.

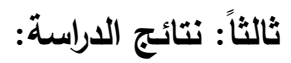
1- أظهرت الدراسة أن هناك اختلاف في الدذاهب الفقهية حول بعض الأمور المتعلقة

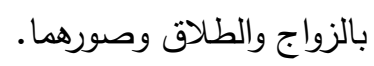
ז- أوضحت الدراسة أن للطلاق أو تنكك الأسرة صوراً وأثنكال متعددة، حيث بستطيع الرحل

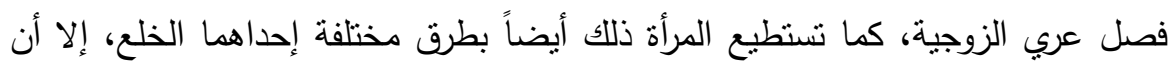
الزوجة نادراً ما تنتكن من تطليق نفسها بإرادتها المنفردة.

مدى الاتفق والاختلاف بين هذه الاراسة والدراسة الحالية:

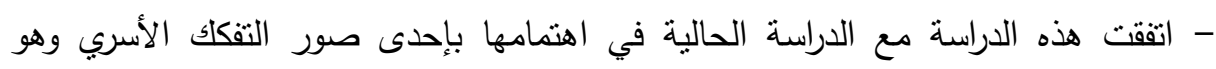
الطلاق عن طريق الخع. - بينما اختلفت الدراستان في طريقة عرضهما للموضوع، حيث اهتمت الدراسة الراهنة بالخلع

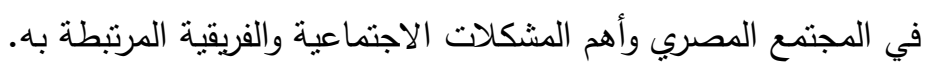

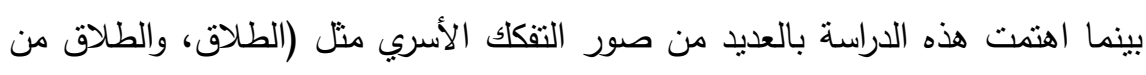

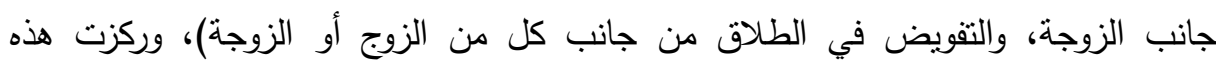

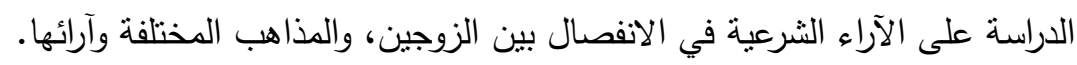

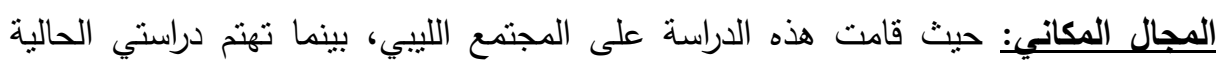

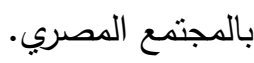


(T) دراسة: Zinsmeister, Karl 2000 (الطلاق يؤذي الأطفال 1- هاف الدراسة: معرفة تأثير الطلاق أو انفصال الوالدين على الأطفال بشكل عام.

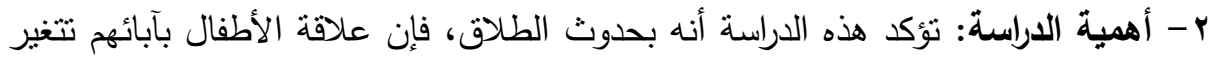

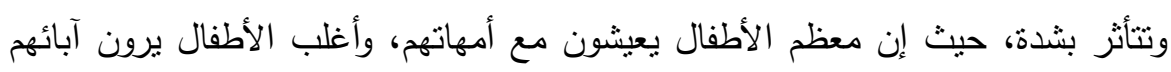

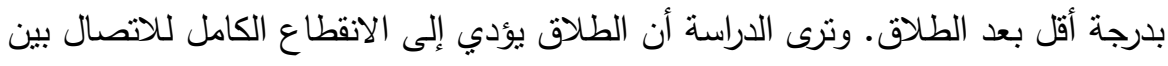

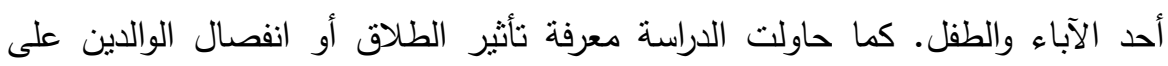

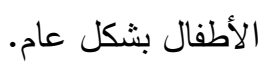

تساؤلات الاراسة وأهدافها: حاولت الداسة الإجابة على التساؤلات التالية:

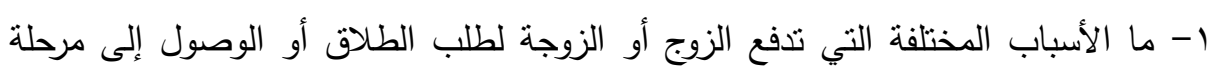

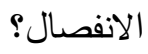
r- با تأثير الطلاق بين الآباء على الأولاد وخصوصاً التحصيل الدراسي للأطفال؟ الأبه

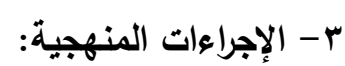

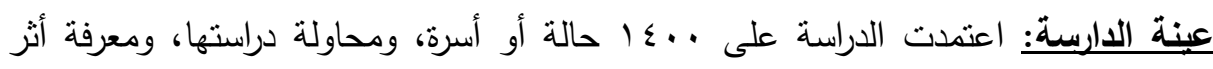
الطلاق على الأطفال في الددى البعيد.

\section{الاطار اللنظيه}

النظريات المفسرة للخلع:

1- نظرية الصراع: يركز أصحاب نظرية الصراع على مسلمة أساسية هي أن العنف الذى

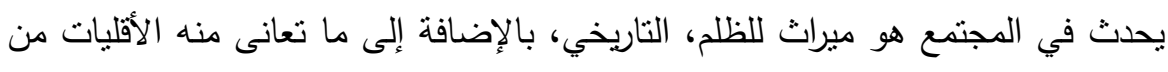
عدم الحصول على نصيب عادل من الثروة. حيث إن التركيز الأساسي في هذا الاتجاه

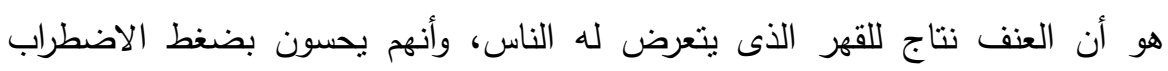

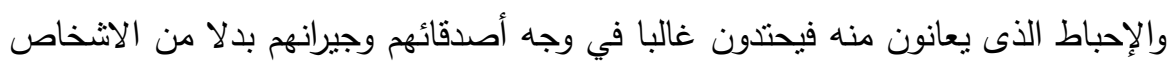
الذين يقهرونهم · وإذا كانت نظرية الصراع تركز على صراع الأدوار فإنها تركز أيضاً على الثعور الثخصي بالحرمان بين ما يرغب فيه الناس وما يحصلون علية، وبين

$$
\text { المجلد السادس والأربعون، الجزء الثالث، يونيو } 9 \text { ــ }
$$


انخفاض المستوى الاقتصادي مع نوافر الحرمان النسبي مما يزيد من النزوح نحو العنف

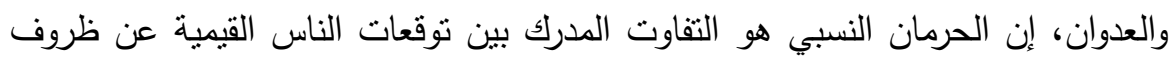
الحياة التي يستحقونها من وجهه نظرهم، وبين قدراتهم في تحقيق هذه الحياة، وأياً كانت

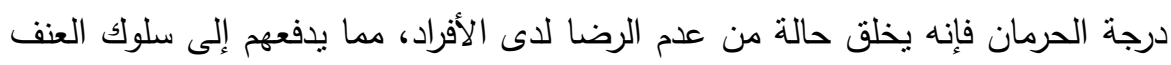
نتيجة للإحساس بالظلم الاجتماعي وانعدام العدالة الاجتماعية وسيطرة القيم المادية. r-نظرية اتجاه ما بعد الحداثة: يقصد بعصر الحداثة العصر الذى امتد منذ بدايات الثورة

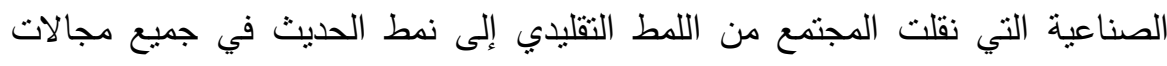

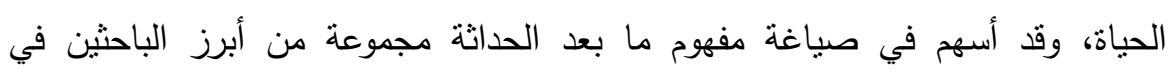
مجالات النقد الأدبي والفلسفة وعلم الاجتماع • وقد أثنار (إدجار) و (جليزر ) (أبرز) ممثلي

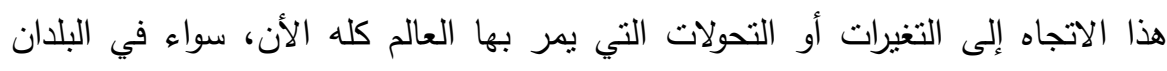

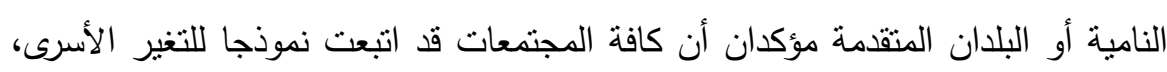
فالأطفال يعيشون على نحو مضطرد معظم فترات طفولتهم داخل أسرة يرعاها أحد الأبوين فقط، وذلك إما بسبب تجنب الزواج في حد ذاته أو بسبب الزيادة الكبيرة في حالات

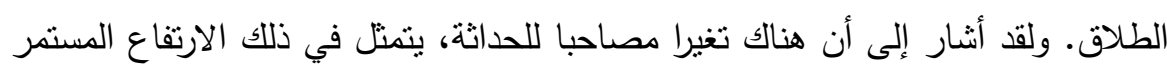

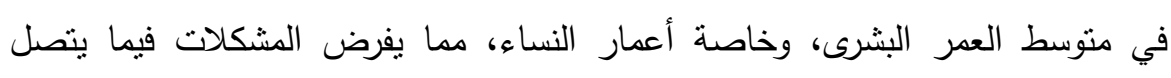

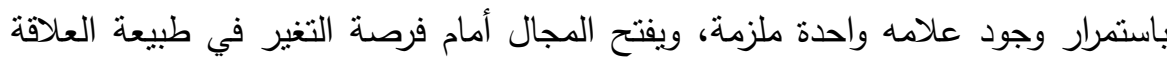
الحميمة على مدى حياة الفرد، فالمسنين مثلا لاسيما النساء يواجهون مشكله اختيار

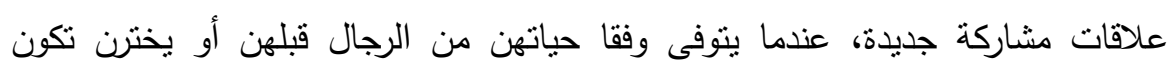
علاقات صداقة مع نظرائهن من المعمرات وهي علاقات يمكن أن تستمر لفترات طويلة. وفي هذا الإطار يؤكد (جيدنز) على أن فهم الممارسات الاجتماعية يمكننا من أن نفهم

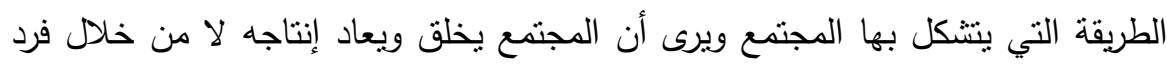
واحد ولكن من خلال المشاركين في كل موقف اجتماعي. ومن هنا قدم (جيدنز) مفهومة

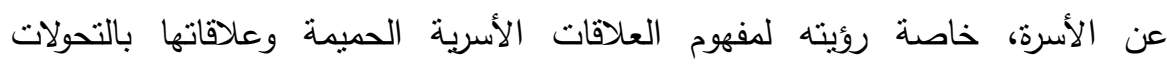
الاجتماعية والاقتصادية والسياسية الجارية. كما أشار إلى أن النظم الجديدة _ـ وخاصة الاصنة

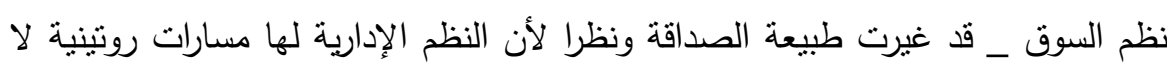


شخصية وغير خاضعة للمعايير الأخلاقية، فإن العلاقات الثخصية المبنية على الإخلاص والثقة تصبح جزءا أساسيا من الحياة الحديثة.

على الرغم من اتفاق علماء الاجتماع على أهمية دراسة المشكلات الاجتماعية وتحديدهم

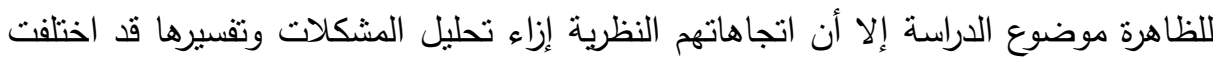
ويرجع ذلك إلى سبيين: الأول يمكن في أن الظاهرة الاجتماعية الواحدة يمكن تحديدها إنهاء وتعريفها من خلال منباينة وذلك لأن كل عالم في تفسيره للظاهرة يتبنى مدرسة فكرية معينة تملى علية اختيار نموذج معين يتم في ضوئه تحديد مشكلة الدراسة ومنهج التحليل و الإطار

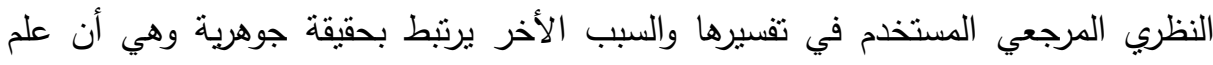
الاجتماع ذاته يعد نتاجا اجتماعيا أو بمعنى أخر أن نظريات ومفاهيم علم الاجتماع قد تتكلت من خلال ظروف اجتماعية وسياسية و اقتصادية معينة

\section{الإجباعايت المنهجيهي}

حدود الاراسة: اقتصرت حدود الدراسة المكانية والزمنية والبشرية على ما يأتي: أ- الحدود المكانية: اقتصرت الحدود المكانية للاراسة الحالية على محافظة بور سعيد باعنبارها يمثلان البيئة الحضرية والريفية.

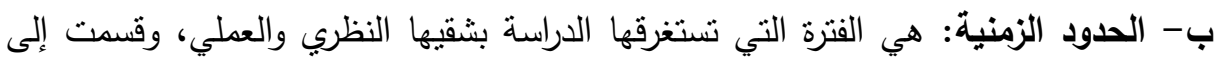
ثلاث مراحل تتمنل في الآتي: -المرحلة الأولى: مرحلة جمع المعطيات والإطار النظري حول موضوع الدراسة من الفترة $(r \cdot 1 \varepsilon / \varepsilon / r \cdot r \cdot 11 / 1 / 1)$

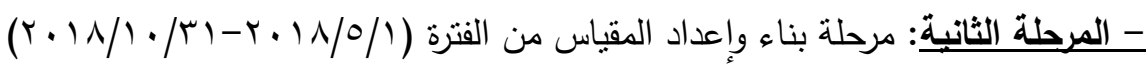
-المرحلة الثالثة: مرحلة جمع وتفريغ البيانات وجدولتها وتحليلها واستخلاص النتائج

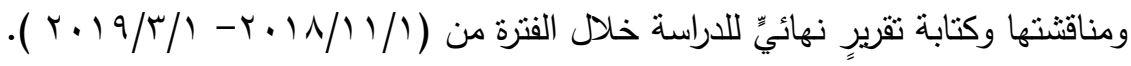




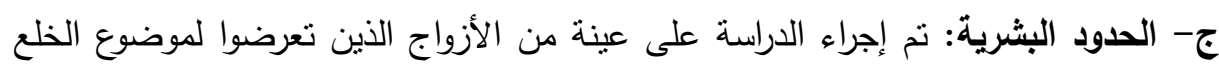

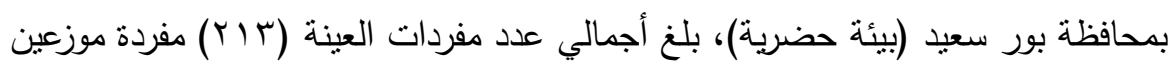
حسب الوزن النسبي بين الأكور والاناث.

عينة الدراسة وأدوات الدراسة:

• استمارة الاستبيان الأولية حسب نوعية البيانات المطلوب جمعها (إعداد الباحثون) • استمارة عبارات الاستبيان المتعلقة بقضية الخلع (إعداد الباحثون)

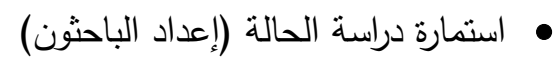

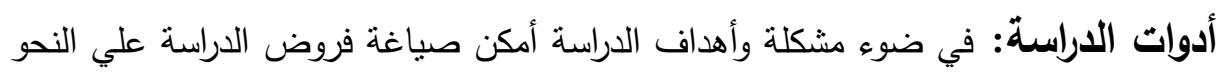
الآتي: فروض الدراسة: • توجد علاقة ذات دلالة أحصائية بين المتغيرات الاجتماعية والفيزيقية المرتبطة بقضيه الخلع والاسباب التي تدفع المرأة لرفع دعاوى الخلع وتأثثر ذلك على ذلى الأسرة والنتائج المرتبطة على المجتمع من انتشار ظاهره قضيه الخلع. توجد علاقة ذات دلالة أحصائية بين متغيرات اجتماعية تؤدى الى قضئه فئيه الخلع. • • توجد علاقة ذات دلالة أحصائية بين متغيرات فيزيقية تؤدى الى قضيه الخلع.

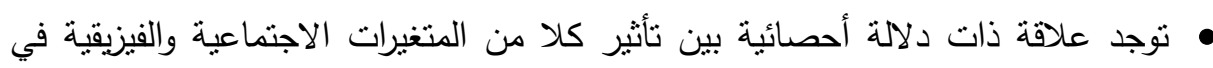
قضية الخع.

• توجد علاقة ذات دلالة أحصائية بين حجم قضايا الخلع في والمجال المكاني للدراسة . • توجد علاقة ذات دلالة أحصائية بين بعض الأسباب الاجتماعية الأخرى أهمها (تدخل فئل

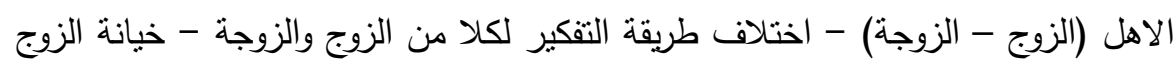
- عدم تحمل الزوج المسئولية - عدم وجود حوار بين الزوجين) التى تؤدى لقضية الخلع

$$
\text { لم بيتم ذكرها. }
$$

• توجد علاقة ذات دلالة أحصائية بين الأسباب الفيزيقية والنفسية التى تؤدى الى الخلع

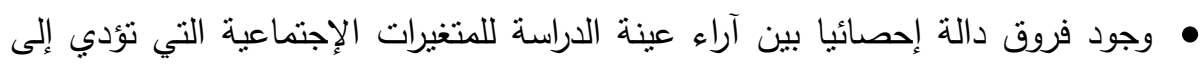

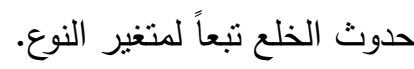


وجود فروق دالة إحصائيا بين متغير النوع للأسباب الفيزيقية والنفسية التي تؤدي إلى

$$
\text { حدوث الخلع. }
$$

وجود فروق دالة إحصائيا بين متغير محل الإقامة للمتغيرات الإجتماعية التي تؤدي إلى

$$
\text { حدوث الخلع. }
$$

وجود فروق دالة إحصائيا تبعاً لمتغير محل الإقامة للأسباب الفيزيقية والنفسية التي تؤدي

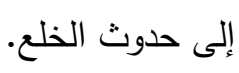

\section{منهبية التربهة}

اعتمدت هذه الدراسة على أسلوب المسح الاجتماعي باستخدام المنهج الوصفي التحليلي

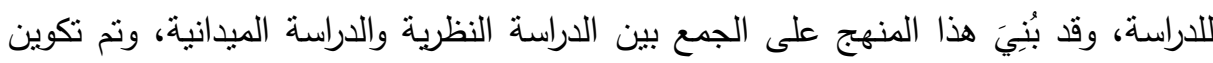
الإطار النظري من خلال تجميع المادة العلمية المتعلقة بالموضوع محل الدين الدراسة من النه •الكتب والدوريات والأبحاث المنشورة باللغة العربية التي نم الحصول عليها من شبكة بلنه

$$
\text { المعلومات الدولية ( Internet ). }
$$

\begin{tabular}{|c|c|c|}
\hline قيمة آلفا & عدد العبارات & أبعاد الاستبيان \\
\hline$\cdot, \lambda \cdot r$ & IY & لمتغيرات الإجتماعبة التى تؤدي إلى حدوث الخلع \\
\hline$\cdot, \wedge 01$ & 1. & الأسباب الفيزيقية والنفسية التي تؤدى الى الخلع \\
\hline$\cdot, \wedge 9 \vee$ & TY & إجمالي الاستبيان \\
\hline
\end{tabular}

• التقارير الصادرة عن المؤتمرات والندوات المتعلقة بالموضوع محل الدراسة.

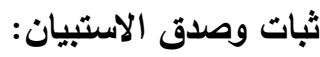

المصدر : جمعت وحسبت من بيانات عينة الدراسة

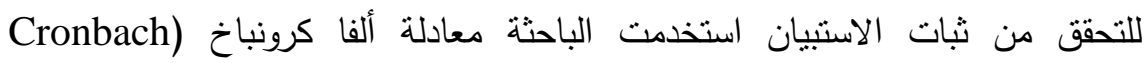
Alpha

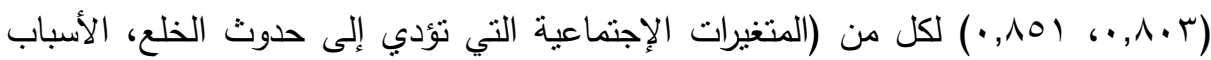
الفيزيقية والنفسية التى تؤدى الى الخلع) على التوالي، وكانت قيمة ألفا لإجمالي الاستبيان

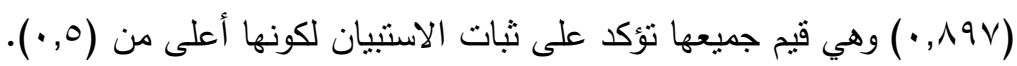


جدول رقم (ץ): صدق الاتساق الداخلي للاستبيان

\begin{tabular}{|c|c|c|}
\hline الالالة المعنوية & معامل ارتباط بيرسون & أبعاد الاستبيان \\
\hline$\cdot, \cdots 1$ & .,9r & المتغيرات الإجتماعية الني تنؤدي إلى حدوث \\
\hline$\cdot, \cdots 1$ & $\cdot 9 \curlyvee \wedge$ & الأسباب الفيزيقية والنفسية التى تؤدى الى \\
\hline
\end{tabular}

المصدر : جمعت وحسبت من بيانات عينة الدراسة

من الجدول السابق لصدق الاتساق الداخلي السابق للاستبيان نجد أن قيم معامل

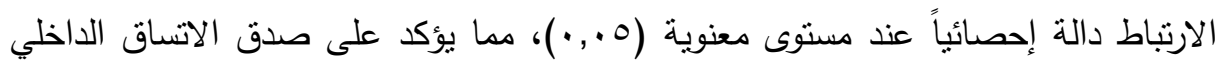

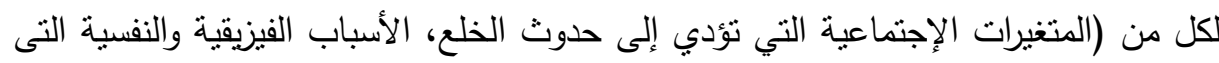

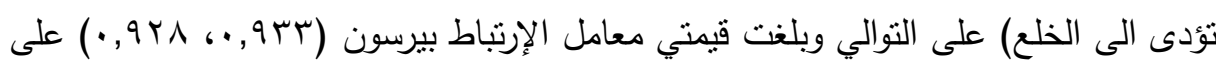

التوالي وهي قيم تؤكد على صدق الاستبيان، وصف البيانات الديموجرافية عينة الدراسة:

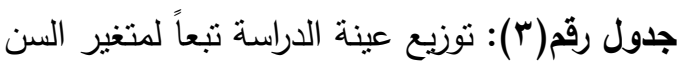

\begin{tabular}{|c|c|c|c|c|}
\hline مستوى المعنويـة & SL & النسبةة & العدد & السن \\
\hline \multirow{5}{*}{$\cdot, \ldots 1$} & \multirow{5}{*}{ Tr } & $0, Y$ & 11 & آقل من · r سنة \\
\hline & & $r \leqslant, \varepsilon$ & OY & מن •r-r.r \\
\hline & & $\varepsilon \varepsilon, 7$ & 90 & آكبر من • .ץ- .؛ \\
\hline & & $r 0, \Lambda$ & 00 & أكبر من •ع - .0 \\
\hline & & $\% 1 \ldots$ & TIT & الاحمال \\
\hline
\end{tabular}

المصدر: جمعت وحسبت من بيانات عينة الدراسة

يشير الجدول السابق لتوزيع عينة الدراسة تبعاً لمتغير السن أن عدد العينة من فئة (أقل

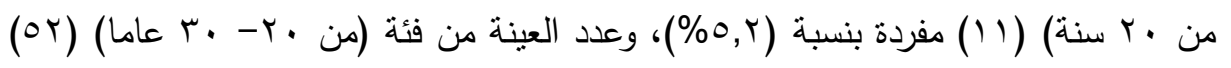

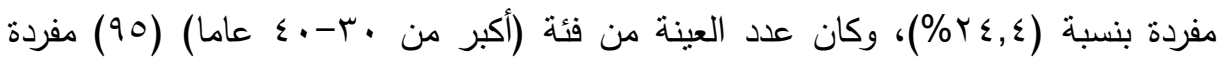

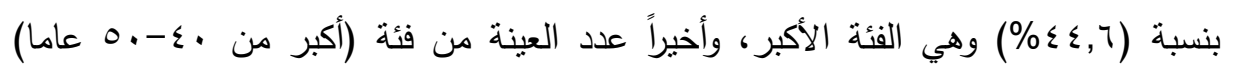

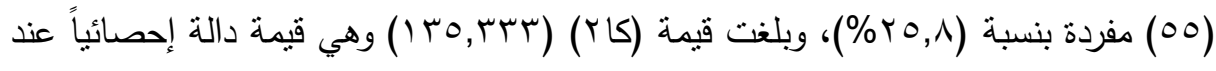
مستوى معنوية (0. . •) مما يشير لوجود فروق بين عينة الدراسة تبعاً لمتغير السن. 
جدول رقم (ع ): توزيع عينة الدراسة تبعاً لمتغير الجنس

\begin{tabular}{|c|c|c|c|c|}
\hline مستوى المعنويـة & 5 & النسبةة & العدد & الجنس \\
\hline \multirow{3}{*}{$\cdot, \cdots 1$} & \multirow{3}{*}{$\mid \vee \neg, \vee \wedge q$} & \%Yч,r & 07 & ذكر \\
\hline & & $\% \vee \Psi, V$ & $10 \mathrm{~V}$ & آنتي \\
\hline & & $\% 1 \ldots$ & TाT & الإجما \\
\hline
\end{tabular}

المصدر: جمعت وحسبت من بيانات عينة الدراسة

من الجدول السابق لوصف عينة الدراسة تبعاً لمتغير النوع ينتين أن عدد الذكور من بانة

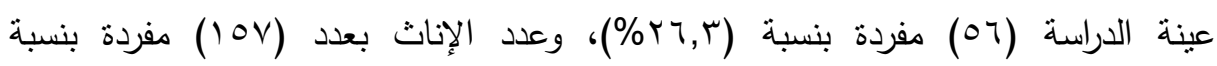

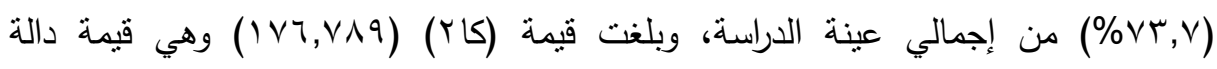
إحصائياً عند مسنوى معنوية (0., •) مما يشير لوجود فروق بين عينة الدراسة تبعاً لمتغير

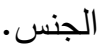
جدول رقم(•): توزيع عينة الدراسة تبعاً لمتغير محل الإقامة

\begin{tabular}{|c|c|c|c|c|}
\hline مستوى المعنوية & SL & النسبة & العدد & محل الإقامة \\
\hline \multirow{3}{*}{$\cdot, \cdots 1$} & \multirow{3}{*}{$\leqslant 7 Y, \wedge \wedge \vee$} & $\% 1 \cdot, \wedge$ & Tr & قرية \\
\hline & & $\% \wedge q, r$ & 19. & مدينة \\
\hline & & $\% 1 \ldots$ & YIT & الإجمالَ \\
\hline
\end{tabular}

المصدر: جمعت وحسبت من بيانات عينة الدراسة

من الجدول السابق لوصف عينة الدراسة تبعاً لمتغير محل الإقامة يتبين أن عدد عينة

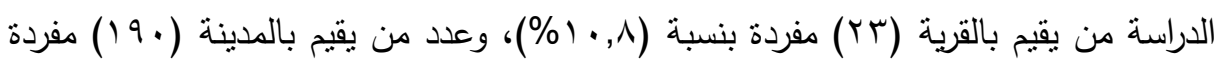

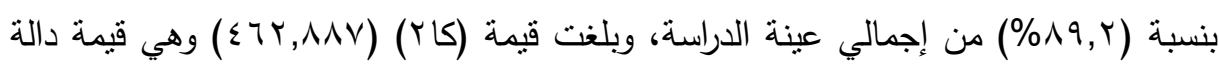
إحصائياً عند مستوى معنوية (0., • ) مما يشير لوجود فروق بين عينة الدراسة تبعاً لمتغير محل الإقامة. 
جدول رقم (†): نوزيع عينة الدراسة تبعاً لمتغير منوسط دخل الأسرة شهرياً بالجنيه (تقريباً)

\begin{tabular}{|c|c|c|c|c|}
\hline المعنوية & كاب & النسبة & العدد & متوسط دخل الأسرة شُهريا بالجنيه \\
\hline \multirow{5}{*}{$\cdot, \cdots 1$} & \multirow{5}{*}{ rᄉ, 9.1} & 9,9 & YI & آقل من ... I ا جنيه \\
\hline & & 77,9 & $1 \leq \mu$ & 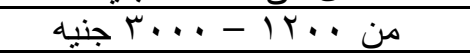 \\
\hline & & $\overline{1 \Lambda, r}$ & rq & آكثز من ... - ... 0 جنيه \\
\hline & & $\varepsilon, V$ & 1 . & أكثر من ... .0 جنيه \\
\hline & & $\% 1 \ldots$ & YIT & الإجمالي \\
\hline
\end{tabular}

المصدر : جمعت وحسبت من بيانات عينة الدراسة

يثير الجدول السابق لتوزيع عينة الدراسة تبعاً لمتغير منوسط دخل الأسرة شهرياً بالجنيه

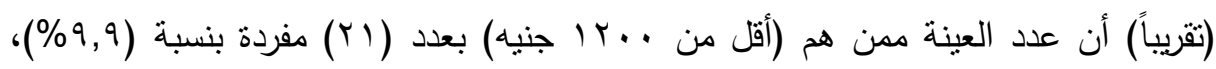

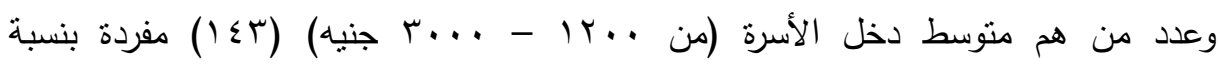

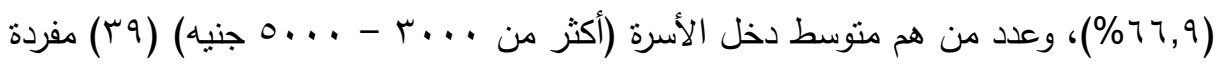

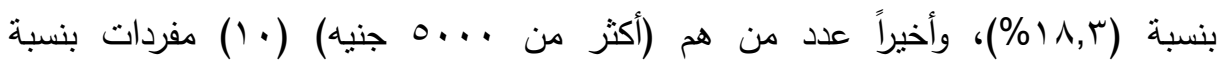

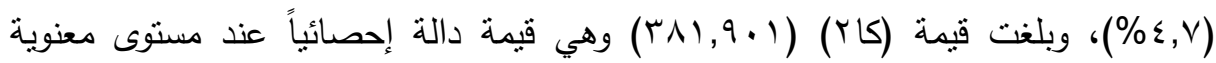

(0. . •) مما يشير لوجود فروق بين عينة الدراسة تبعاً لمتغير متوسط دخل دالئ الأسرة شهرياً

بالجنيه (ثقريباً).

جدول رقم (V): نوزيع عينة الدراسة تبعاً لدتغير عدد أفراد الأسرة

\begin{tabular}{|c|c|c|c|c|}
\hline مستوى المعنويـة & SL & النسبةة & العدد & عدد آقُراد الآسرة \\
\hline \multirow{5}{*}{$\cdot, \cdots 1$} & \multirow{5}{*}{$1 \leqslant \wedge, \wedge 9 \vee$} & $\varepsilon 9, r$ & 1.0 & من ب-r أفراد \\
\hline & & $\S 1, \wedge$ & 199 & من ع-ه أفراد \\
\hline & & $\Lambda, 0$ & 11 & من Y- V- أفراد \\
\hline & &., 0 & 1 & من V أفراد فأكثر \\
\hline & & $\% 1 \ldots$ & YIT & الإجمالى \\
\hline
\end{tabular}

المصدر : جمعت وحسبت من بيانات عينة الدراسة

يشير الجدول السابق لتوزيع عينة الدراسة تبعاً لمتغير عدد أفراد الأسرة أن عدد العينة

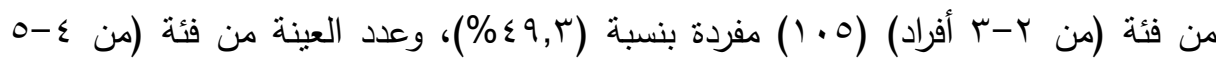

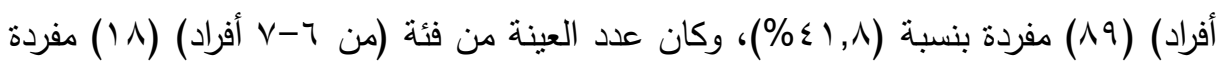

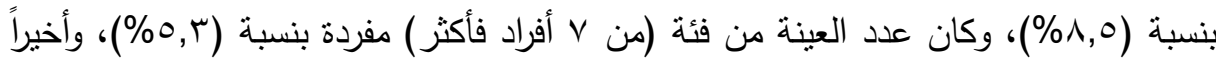

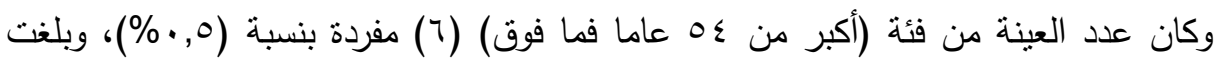




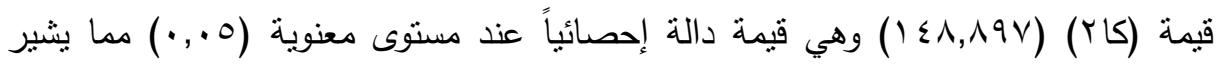
لوجود فروق بين عينة الدراسة تبعاً لمتغير عدد أفراد الأسرة.

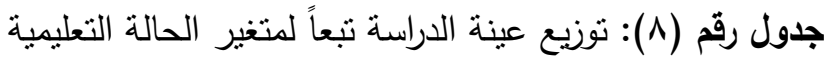

\begin{tabular}{|c|c|c|c|c|}
\hline مستوى المعنوية & SL & النسبة & العدد & الحالة التعليمية \\
\hline \multirow{6}{*}{$\cdot, \cdots 1$} & \multirow{6}{*}{ 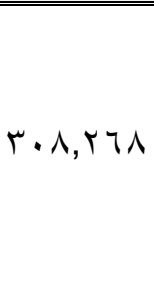 } & $\overline{T, r}$ & 0 & آمسة \\
\hline & & 0,7 & IT & ثقراً وتكتب \\
\hline & & Yo, $\varepsilon$ & $0 \leqslant$ & مؤهل متوسط \\
\hline & & $O V, V$ & ITr & مؤهل جامعي \\
\hline & & 1,9 & 19 & مؤهل فوق الجامعي \\
\hline & & $\% 1 \ldots$ & TाT & الإجمالح \\
\hline
\end{tabular}

المصدر: جمعت وحسبت من بيانات عينة الدراسة

يثير الجدول السابق لتوزيع عينة الدراسة تبعاً لهتغير الحالة التعليمية أن عدد العينة

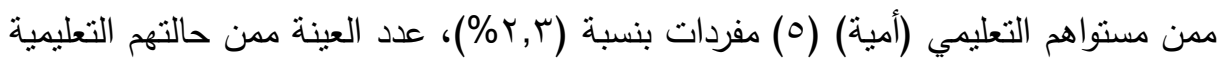

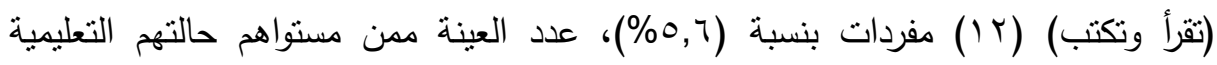

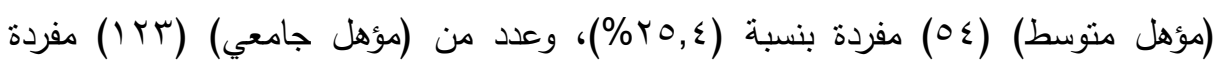

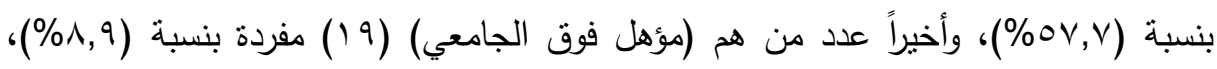

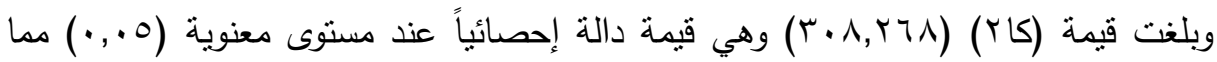
يثير لوجود فروق بين عينة الدراسة تبعاً لمتغير الحالة التعليمية.

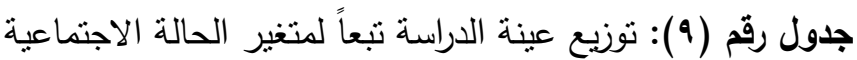

\begin{tabular}{|c|c|c|c|c|}
\hline مستوى المعنوية & SL & النسبة & العدد & الحالة الاجتماعية \\
\hline \multirow{7}{*}{$\cdot, \cdots 1$} & \multirow{7}{*}{$r 01, \cdot V}$. & $11, V$ & To & آعزب \\
\hline & & $\leqslant 0,1$ & 97 & متزوج \\
\hline & & $r, \Lambda$ & 7 & عاقد قرآن \\
\hline & & $\mathrm{V}$ & 10 & مطلق \\
\hline & & $r \cdot, l$ & $7 \varepsilon$ & خلع \\
\hline & & $r, r$ & $\mathrm{~V}$ & آرمل \\
\hline & & $\% 1 \ldots$ & $r \mid r$ & الإجمال \\
\hline
\end{tabular}

المصدر : جمعت وحسبت من بيانات عينة الدراسة 
يشير الجدول السابق لتوزيع عينة الدراسة تبعاً لمتغير الحالة الاجتماعية أن عدد العينة

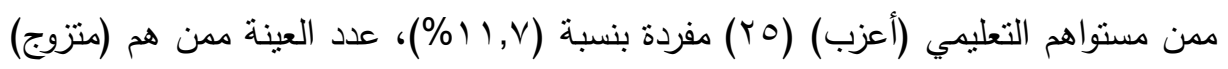

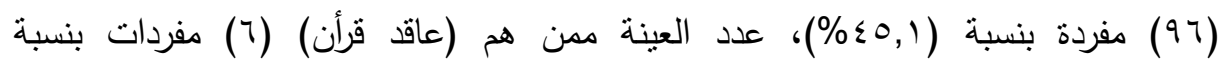

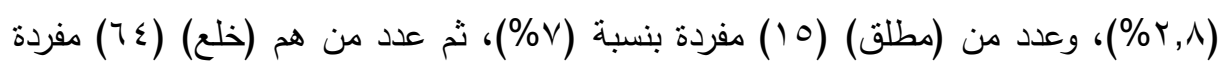

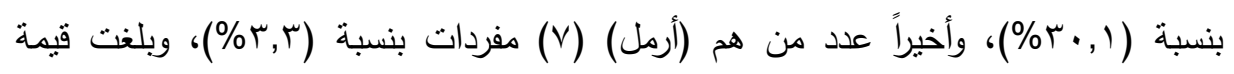

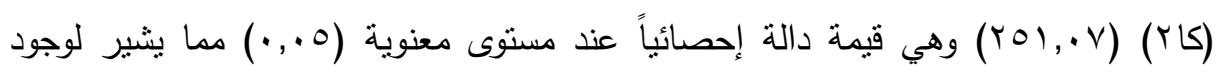
فروق بين عينة الدراسة تبعاً لمتغير المؤهل الدراسي.

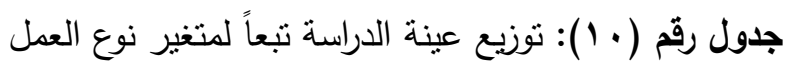

\begin{tabular}{|c|c|c|c|c|}
\hline مستوى المعنويـة & Sا & النسبة & العدد & نوع العمل \\
\hline \multirow{5}{*}{$\cdot, \cdots 1$} & \multirow{5}{*}{ ח } & OY, I & 111 & موظف حكومح \\
\hline & & $T \cdot, V$ & $\varepsilon \leqslant$ & موظف قطاع خاص \\
\hline & & $V, 0$ & 17 & اعمال حرة \\
\hline & & $19, V$ & $\sum Y$ & لا يعمل \\
\hline & & $\% 1 \ldots$ & TIT & الإجمالح \\
\hline
\end{tabular}

المصدر: جمعت وحسبت من بيانات عينة الدراسة

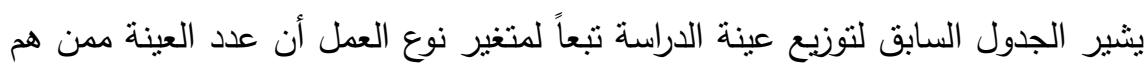

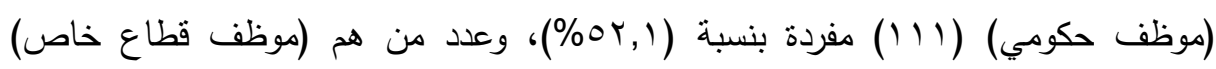
(§

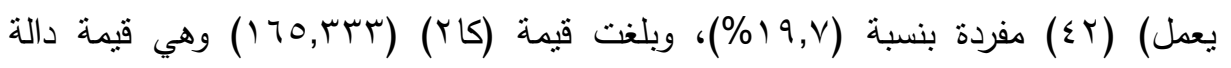
إحصائياً عند مستوى معنوية (0. . . ) مما يشير لوجود فروق بين عينة الدراسة تبعاً لمتغير نوع العمل. 


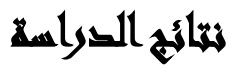

التساؤل الاول: هل هناك متغيرات فيزيقية ونفسية نؤدى الى حدوث الخلع؟

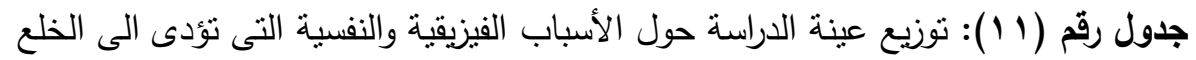

\begin{tabular}{|c|c|c|c|c|c|c|c|c|c|c|}
\hline \multirow[b]{2}{*}{ المنوية } & \multirow[b]{2}{*}{ كاY } & \multirow[b]{2}{*}{ الأهمية } & \multirow{2}{*}{ المرجح } & \multicolumn{2}{|c|}{$\bar{~}$} & \multicolumn{2}{|c|}{ الى حد ما } & \multicolumn{2}{|c|}{ نعم } & \multirow[b]{2}{*}{ العبارات } \\
\hline & & & & $\%$ & ك & $\%$ & s & $\%$ & s & \\
\hline$\cdot, \ldots 1$ & $1 \leq 0, r \wedge$ & 9 & $\Lambda \Lambda, 1$ & v & 10 & 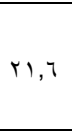 & $\leq 7$ & $v_{1}, \varepsilon$ & $10 r$ & إهمال الزوج التعرف على الزوجة \\
\hline,,$\ldots 1$ & $\leq \tau r, q \leq$ & r & $90, r$ & $r, \Lambda$ & 7 & $\Lambda, 0$ & 11 & $\Lambda \Lambda, \vee$ & 119 & 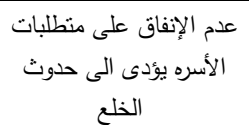 \\
\hline,,$\ldots 1$ & $|V|, r V$ & 1 & $9 \wedge, r$ & . & . & $0, r$ & 11 & $9 \leqslant, \Lambda$ & T. & المستمرة يؤدى إلى حدوث والاهانة \\
\hline$\cdot, \ldots 1$ & $1 A ., r_{0}$ & v & $9 \cdot, 7$ & $r, \wedge$ & $\wedge$ & $r \cdot, V$ & $\varepsilon \varepsilon$ & $v_{0, T}$ & 171 & 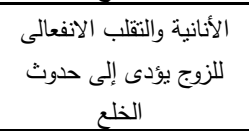 \\
\hline$\cdot, ., 1$ & $r \leqslant q, v r$ & 7 & $91, v$ & $\varepsilon, V$ & 1. & 10,0 & r & $\vee ৭, \wedge$ & iv. & في كافه جوانب الحياه دون الزون \\
\hline$\cdot, \ldots 1$ & & $\varepsilon$ & $9 Y, T$ & $r, \wedge$ & 7 & $17, \varepsilon$ & ro & $\wedge \cdot, \wedge$ & IVT & 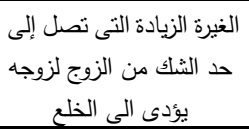 \\
\hline$\cdot, \cdots 1$ & $r \leq 0,1 \wedge$ & $r$ & $9 \Gamma, \varepsilon$ & $r, \wedge$ & $\wedge$ & 17,9 & «1 & $\vee q, r$ & 179 & 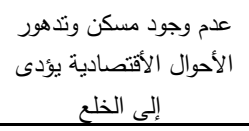 \\
\hline$\cdot, ., 1$ & $r V V, V T$ & $\wedge$ & $\Lambda \wedge, \mathrm{V}$ & 7,7 & $1 \leq$ & $r \cdot, V$ & $\varepsilon \varepsilon$ & $V Y, \Lambda$ & 100 & تدخل الأمن الطرفين يؤدى \\
\hline,,$\ldots 1$ & $191, \cdot r$ & 1. & $\Lambda \varepsilon, \varepsilon$ & $11, v$ & ro & $r r, 0$ & 0 . & I & $1 \mathrm{r}$ & الطرفين يؤدى الإلى الخلى من \\
\hline$\cdot, \ldots 1$ & $r_{0} \leqslant, V T$ & 。 & $9 r, r$ & $r, \wedge$ & 7 & $\mid v, \varepsilon$ & rv & $\vee १, \wedge$ & iv. & الزوجين يؤدى إلى الخلع بلين \\
\hline
\end{tabular}

المصدر: جمعت وحسبت من بيانات عينة الدراسة 
يشير الجدول السابق لتوزيع إجابة عينة الدراسة حول الأسباب الفيزيقية والنفسية التى تؤدى الى حدوث الخلع إلى ما يلي:

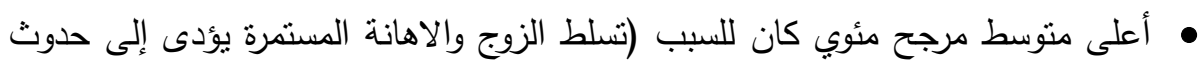

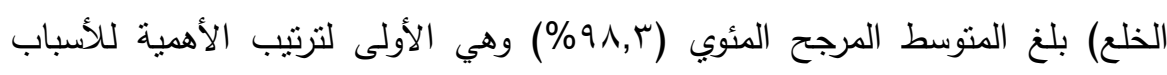
الفيزيقية والنفسية التى تؤدى إلى حدوث الخلع من وجهة نظر المبحوثين، وبلغت قيمة

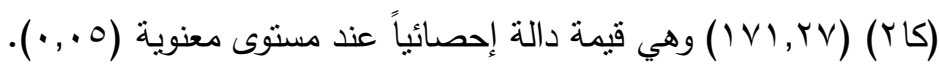

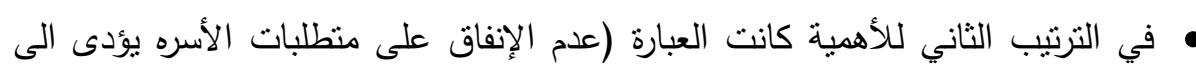

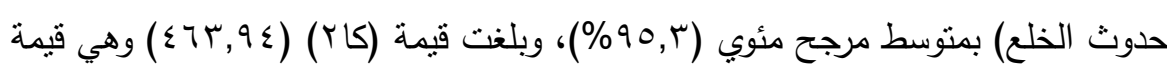

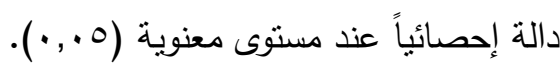

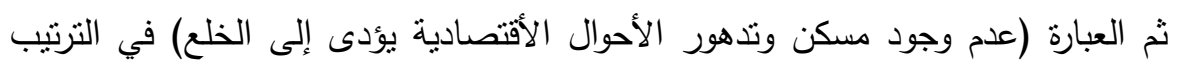

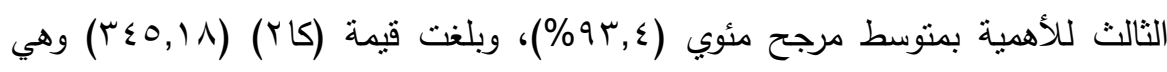
قيمة دالة إحصائياً عند مستوى معنوية (0. . •).

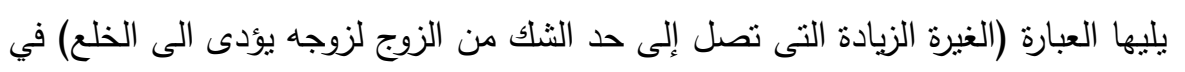

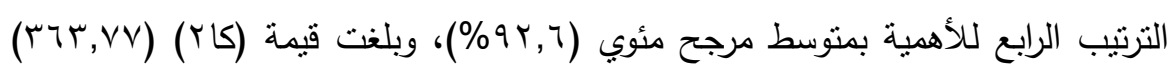

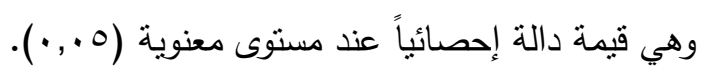
كانت العبارة (الجمود العاطفى بين الزوجين يؤدى إلى الخلع) في الترتيب الخامس للأهمية

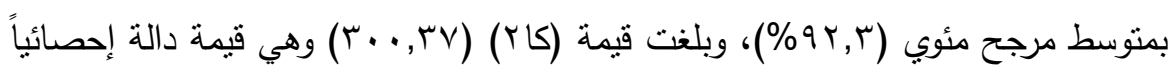

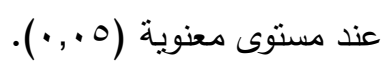

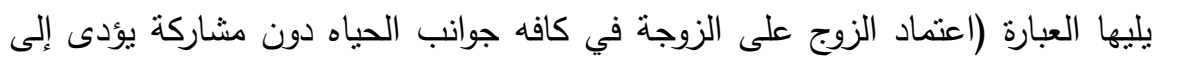

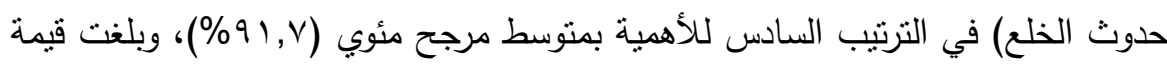

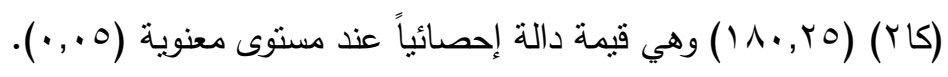

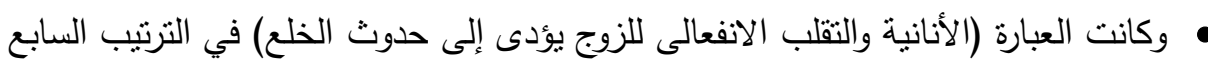

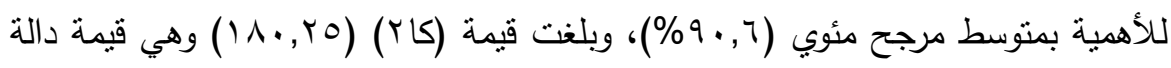

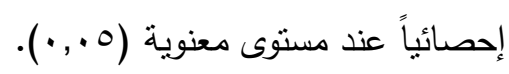




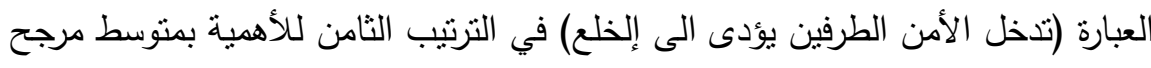

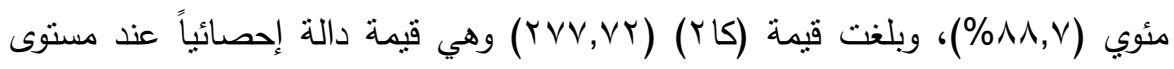

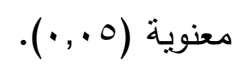

العبارة (إهمال الزوج التعرف على ميول الزوجة يؤدى إلى حدوث الخلع) في الترتيب

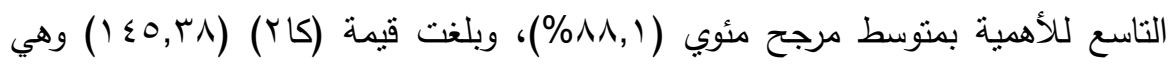

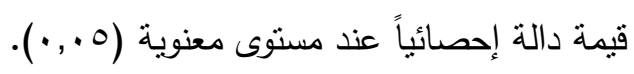

التساؤل الاول: هل توجد فروق دالة إحصائيا بين آراء عينة الدراسة للمتغيرات الإجتماعية التي تؤدي إلى حدوث الخلع تبعاً لمتغير النوع.

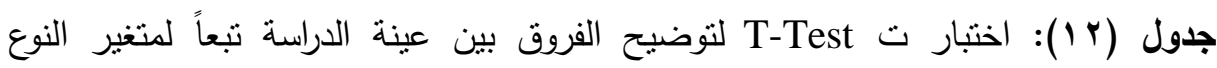

\begin{tabular}{|c|c|c|c|c|c|c|}
\hline المعنوية & قيمة ت & المعياري & الوسط الحسابي & 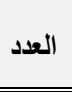 & | الجنس & المتغيرات \\
\hline \multirow{2}{*}{$\cdot, \cdot 1$} & \multirow{2}{*}{$r, 019$} & $\varepsilon, r_{0}$ & r, ro & 00 & | ذكر & \multirow{2}{*}{ المتغيرات الإجتماعبة التي تؤدي إلى } \\
\hline & & $r, 01$ & $r, \wedge q$ & $10 \mathrm{~V}$ & انثى & \\
\hline الدلالة المعنوية & قيمة ت & الإنحراف المعياري & |الوسط الحسابي & العدد & | الجنس & المتغيرات \\
\hline \multirow[t]{2}{*}{$\cdot, .1$} & $r, 7.0$ & $\varepsilon, \cdot r$ & rT, & 00 & | ذا ل ذكر & \multirow{2}{*}{ الأسباب الفيزيقية والنفسية التي تؤدي } \\
\hline & & $r, \leqslant 0$ & $Y V, Y)$ & $10 \mathrm{~V}$ & انثى & \\
\hline | الدلالة المعنوية & قيمة ت & الإنحراف المعياري & |الوسط الحسابي & 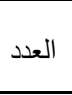 & الإقامة & المتغيرات \\
\hline \multirow[t]{2}{*}{$\cdot, .7$} & $1,9 \cdot 7$ & $\varepsilon, 1 Y$ & $r \cdot, 0 \leqslant$ & 14 & قرية & \multirow{2}{*}{ المتغيرات الإجتماعية التي نؤدي إلى الخد } \\
\hline & & $r, v \leq$ & Mr,T. & 119 & ريف & \\
\hline |الدلالة المعنوية & قيمة ت & |لإنحراف المعياري| & الوسط الحسابي & 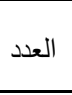 & الإقامة & المتغيرات \\
\hline \multirow[t]{2}{*}{$\cdot, \cdots 1$} & r, rro & $\varepsilon, \cdot r$ & $r \varepsilon, \cdot \Lambda$ & 15 & | ذكر & \multirow{2}{*}{ 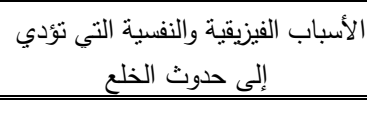 } \\
\hline & & $r, \uparrow$. & $r V, \varepsilon \varepsilon$ & 119 & انثى & \\
\hline
\end{tabular}

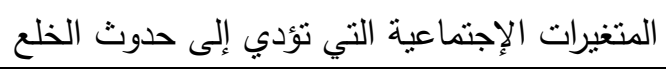

المصدر : جمعت وحسبت من بيانات عينة الدراسة 
تبين من الجدول السابق للفروق بين عينة الدراسة تبعاً لمتغير النوع للمتغيرات

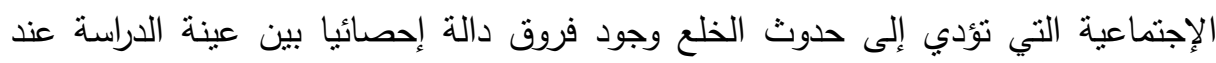

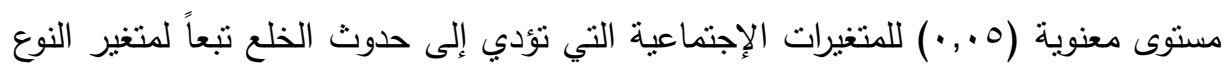

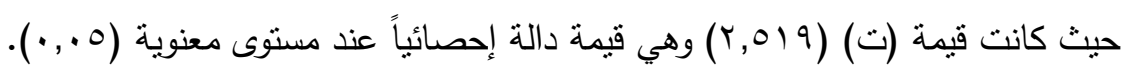
التساؤل الخامس: هل توجد فروق دالة إحصائيا بين آراء عينة الدراسة للأسباب الفيزيقية التي

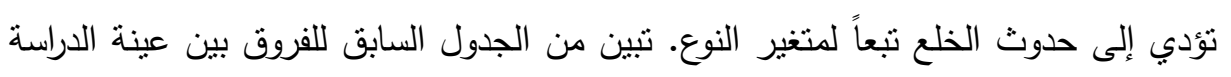

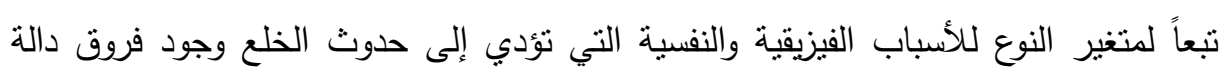

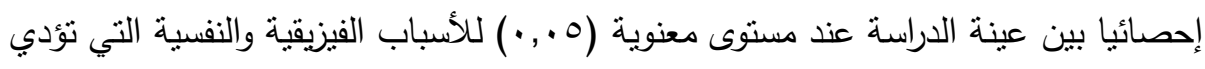

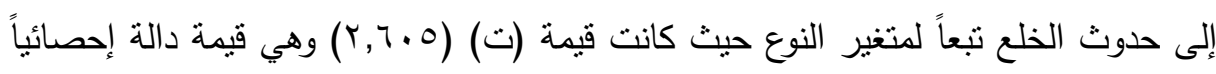
عند مستوى معنوية (0. . •). التساؤل السادس: هل توجد فروق دالة إحصائيا بين آراء عينة الدراسة للمتغيرات الإجتماعية

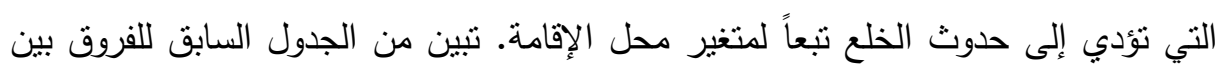

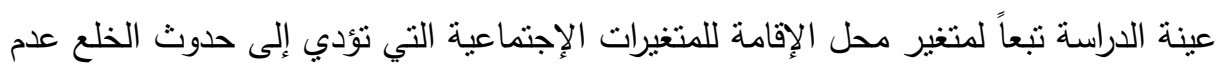

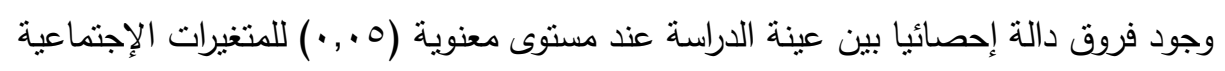

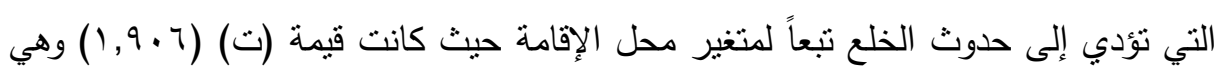
قيمة غير دالة إحصائياً عند مستوى معنوية (0. . . ).

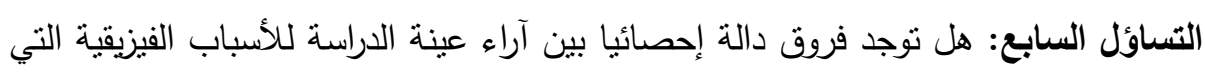

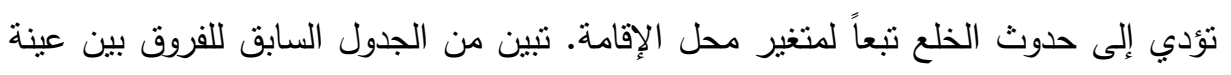

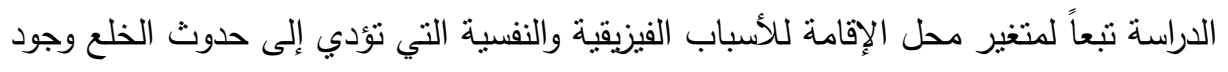

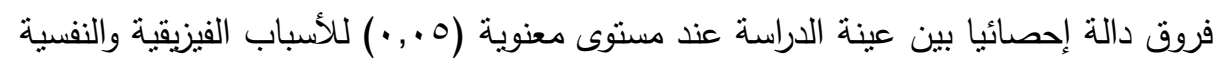

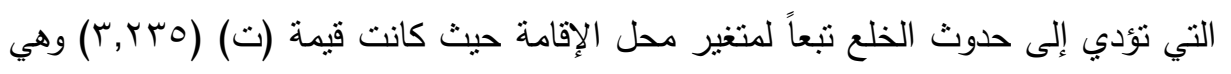
قيمة دالة إحصائباً عند مسنوى معنوية (0. • . •). التساؤل الثامن: هل توجد فروق دالة إحصائيا بين آراء عينة الدراسة للمتغيرات الإجتماعية التي تؤدي إلى حدوث الخلع تبعاً لمتغير الحالة التعليمية. 
جدول(r 1): اختبار التباين ANOVA لحساب دلالة الفروق بين متوسطات درجات آراء عينة

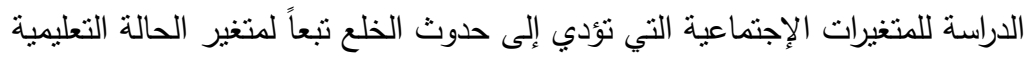

\begin{tabular}{|c|c|c|c|c|c|c|}
\hline المعنوية & قَّمة & الإمعياري & المتوسط & العدد & \multicolumn{2}{|c|}{ المتغيرات } \\
\hline \multirow{6}{*}{$\cdot, \cdots r$} & \multirow{6}{*}{$\varepsilon, \varepsilon \cdot 1$} & $0,1 \mathrm{~V}$ & $r q, \wedge$. & 0 & آمية & \multirow{6}{*}{ التى الإجتماعيراتية } \\
\hline & & $\varepsilon, \Psi Y$ & $r 1,9 r$ & $1 T$ & تقراً وتكتب & \\
\hline & & $\varepsilon, \cdot Y$ & $\mu, \Sigma 1$ & $0 \leq$ & مؤهل متوسط & \\
\hline & & $r, \leqslant 0$ & $r T, r T$ & ITr & مؤهل جامعى & \\
\hline & & $r, r \varepsilon$ & $\Gamma \cdot, \wedge \varepsilon$ & 19 & مؤهل فوق الجامعي & \\
\hline & & $\Gamma, \wedge$. & $r Y, \leqslant 0$ & YIT & الإجمالى & \\
\hline
\end{tabular}

المصدر: جمعت وحسبت من بيانات عينة الدراسة

يتبين من الجدول السابق لحساب دلالة الفروق بين متوسطات درجات آراء عينة الدراسة

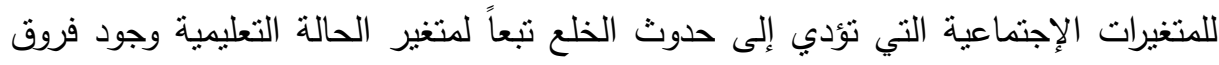

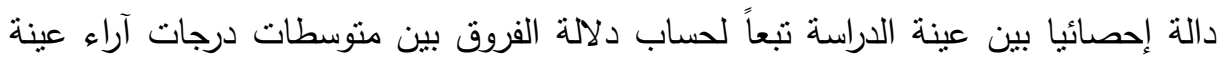

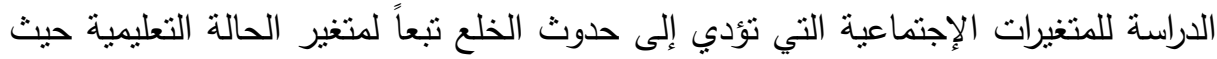

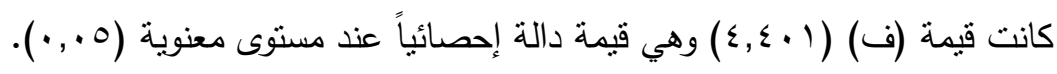
التساؤل التاسع: هل توجد فروق دالة إحصائيا بين آراء عينة الدراسة للأسباب الفيزيقية التي تؤدي إلى حدوث الخلع تبعاً لمتغير الحالة التعليمية. جدول(§ 1): اختبار التباين ANOVA لحساب دلالة الفروق بين متوسطات درجات آراء عينة

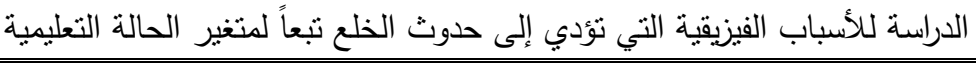

\begin{tabular}{|c|c|c|c|c|c|c|}
\hline المعنوية & قيمة ف & المالمعياري & المتوسط & العدد & \multicolumn{2}{|c|}{ المتغيرات } \\
\hline \multirow{6}{*}{$\cdot, \cdot 9$} & \multirow{6}{*}{$r, .01$} & $\mu, \cdot \Lambda$ & rq, , & 0 & آمية & \multirow{6}{*}{ الإجتماعية إلى التي حدوثي } \\
\hline & & $r, v)$ & Y & IT & تقراً وتكتب & \\
\hline & & $r, \wedge$. & YT,ro & $0 \leqslant$ & مؤهل متوسط & \\
\hline & & $r, 0$. & $r V, \wedge q$ & ITr & مؤهل جامعي & \\
\hline & & $r, q 1$ & Yq,Vq & 19 & مؤهل فوق الجامعي & \\
\hline & & $r, 7 \tau$ & $r V, r$. & 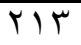 & الإجمالى & \\
\hline
\end{tabular}

المصدر: جمعت وحسبت من بيانات عينة الدراسة 
يتبين من الجدول السابق لحساب دلالة الفروق بين متوسطات درجات آراء عينة الدراسة

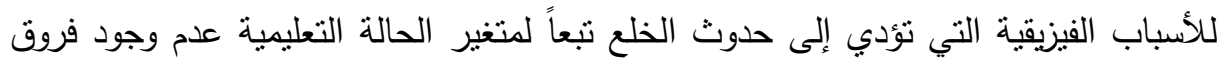

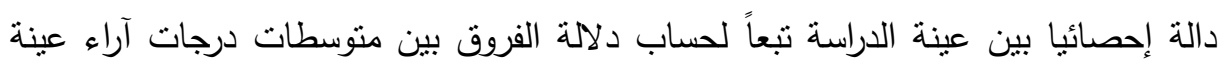

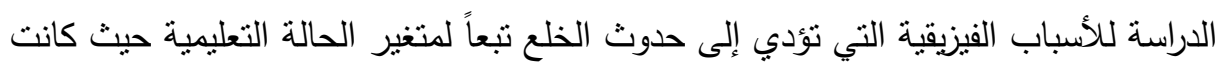

$$
\text { قيمة (ف) (r,01.01) وهي قيمة غير دالة إحصائياً عند مستوى معنوية (0. . . ). }
$$
التساؤل العاشر: هل توجد فروق دالة إحصائيا بين آراء عينة الدراسة للمتغيرات الإجتماعية التي تؤدي إلى حدوث الخلع تبعاً لمتغير السن. جدول(10): اختبار التباين ANOVA لحساب دلالة الفروق بين متوسطات درجات آراء عينة

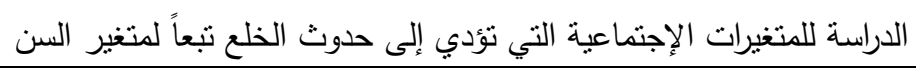

\begin{tabular}{|c|c|c|c|c|c|c|}
\hline المعنوية & قيمة ف & الإِحعرافي & |المتوسط & العدد & \multicolumn{2}{|c|}{ المتغيرات } \\
\hline \multirow{5}{*}{$\cdot, \cdot r$} & \multirow{5}{*}{$r, r \circ \Lambda$} & $r, Y \leqslant$ & $r 9, \leqslant 0$ & 11 & آقل من · r سنة & \multirow{5}{*}{ التى تؤديرات إلإجى حدوثاعية } \\
\hline & & $r, \wedge Y$ & $\Gamma 1,9 \varepsilon$ & Or & s. & \\
\hline & & $r, 79$ & Tr,q & 90 & 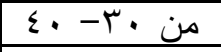 & \\
\hline & & $\Gamma, \wedge \varepsilon$ & $r Y, 79$ & 00 & من .ـ - 0. & \\
\hline & & $r, \wedge$. & Mr, $\leqslant 0$ & 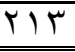 & الإجمالى & \\
\hline
\end{tabular}

المصدر: جمعت وحسبت من بيانات عينة الدراسة

يتبين من الجدول السابق لحساب دلالة الفروق بين منوسطات درجات داته آراء عينة الدراسة

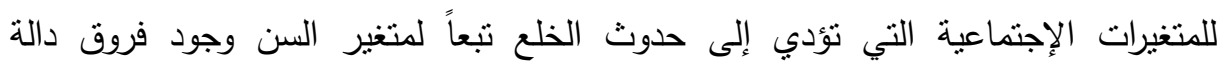
إحصائيا بين عينة الدراسة تبعاً لحساب دلالة الفروق بين متوسطات درجات آلآدئ آراء عينة الدراسة

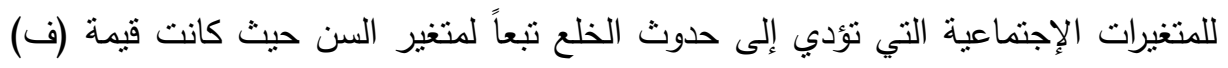

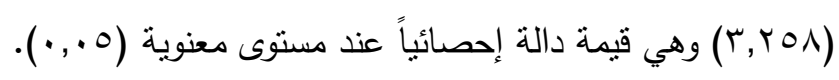

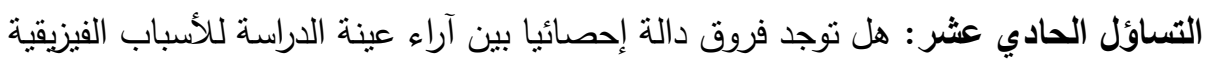
التي تؤدي إلى حدوث الخلع تبعاً لمتغير السن. 
جدول(ף 1): اختبار التباين ANOVA لحساب دلالة الفروق بين متوسطات درجات آراء

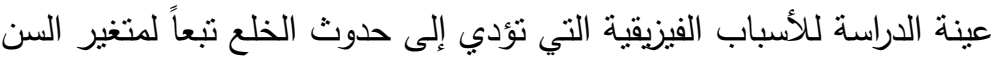

\begin{tabular}{|c|c|c|c|c|c|c|}
\hline المعنوية & قيمة ف & الإِنحياريف & المتوسط & العدد & \multicolumn{2}{|c|}{ المتغيرات } \\
\hline \multirow{5}{*}{$\cdot, \cdots r$} & \multirow{5}{*}{ דוא } & $r, \leqslant q$ & Tr,AY & 111 & آقل من · r سنة & \multirow{5}{*}{ تؤدي إلى حدياب الفيزيقة التئ } \\
\hline & & $r, 0 Y$ & $Y 7,7 Y$ & OY & من •r. r. & \\
\hline & & $r, v \cdot$ & $r V, V O$ & 90 & من •r- • & \\
\hline & & $r, \mu$ & $T V, \Lambda V$ & 00 & מن .؛ - .0. & \\
\hline & & $\Gamma, 7 \tau$ & $r V, r$. & YIT & الإجمالي & \\
\hline
\end{tabular}

المصدر: جمعت وحسبت من بيانات عينة الدراسة

يتبين من الجدول السابق لحساب دلالة الفروق بين متوسطات درجات آراء عينة الدراسة

للأسباب الفيزيقية الني تؤدي إلى حدوث الخلع تبعاً لمتغير السن وجود فروق دالة إحصائيا

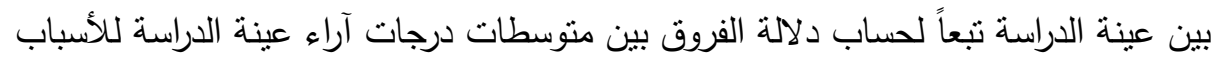

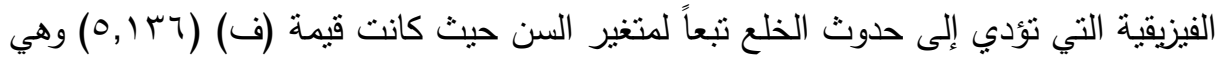
قيمة دالة إحصائياً عند مستوى معنوية (0. ث. . •).

التساؤل الثاني عشر: هل توجد فروق دالة إحصائيا بين آراء عينة الدراسة للتتغيرات الإجتماعية التي تؤدي إلى حدوث الخلع تبعاً لمتغير حالة العمل. جدول (IV): اختبار التباين ANOVA لحساب دلالة الفروق بين متوسطات درجات آراء عينة

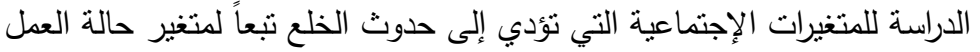

\begin{tabular}{|c|c|c|c|c|c|c|}
\hline المعنوية & قيمة ف & الإلمعحرافي & المتوسط & العدد & \multicolumn{2}{|c|}{ المتغيرات } \\
\hline \multirow{5}{*}{$\cdot, \cdots 1$} & \multirow{5}{*}{$40, .91$} & $Y, V \wedge$ & $T \varepsilon, Y Y$ & 111 & موظف حكومى & \multirow{5}{*}{ الإجتماعية التئي التي حدوثي } \\
\hline & & $r, 7 r$ & MY,YY & $\varepsilon \varepsilon$ & موظف قطاع خاص & \\
\hline & & $r, \wedge V$ & YV,VO & 17 & أعمال حره & \\
\hline & & $r, 1$. & Yq,7V & $\varepsilon Y$ & لا آعمل & \\
\hline & & $\Gamma, \Lambda$. & $r r, \leqslant 0$ & $\overline{T ा T}$ & الإجمالي & \\
\hline
\end{tabular}

المصدر : جمعت وحسبت من بيانات عينة الدراسة 
يتبين من الجدول السابق لحساب دلالة الفروق بين منوسطات درجات آراء عينة الدراسة

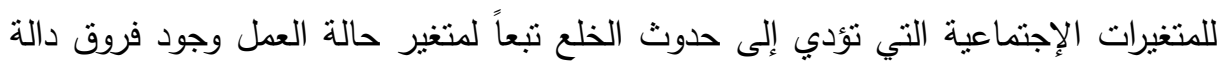

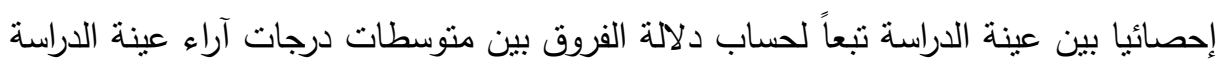

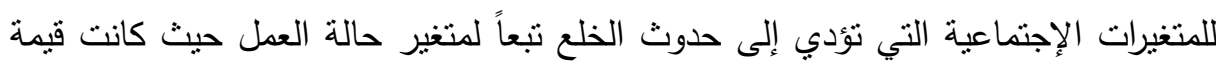

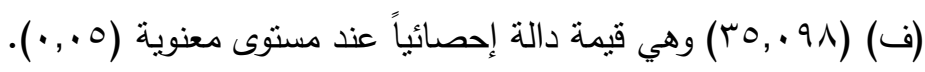

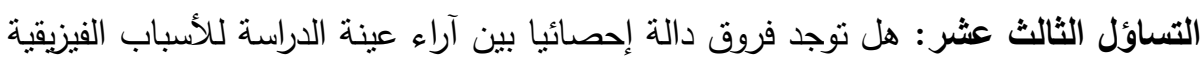
التي تؤدي إلى حدوث الخلع تبعاً لمتغير حالة العمل. جدول(1) 1): اختبار التباين ANOVA لحساب دلالة الفروق بين متوسطات درجات آراء عينة

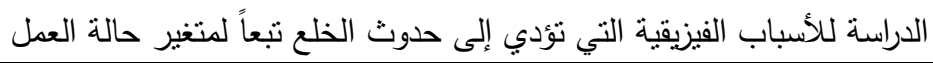

\begin{tabular}{|c|c|c|c|c|c|c|}
\hline المعنوبة & قيمة ف & الإلمعرافي & المتوسط & العدد & \multicolumn{2}{|c|}{ متغيرات } \\
\hline \multirow{5}{*}{$\cdot, \ldots 1$} & \multirow{5}{*}{$r \cdot, V \wedge r$} & $r, V T$ & $r \wedge, 90$ & 111 & موظف حكومى & \multirow{5}{*}{ التحى تؤدي النيزئية } \\
\hline & & $r, 01$ & $Y V, Y V$ & $\varepsilon \varepsilon$ & موظف قطاع خاصر & \\
\hline & & $r, 00$ & $r r, q \varepsilon$ & 17 & أعمال حره & \\
\hline & & $r, 1 \wedge$ & $r \xi, Y T$ & $\varepsilon r$ & لا أعمل & \\
\hline & & $r, 77$ & $r V, r$. & TIT & الإجمالي & \\
\hline
\end{tabular}

المصدر: جمعت وحسبت من بيانات عينة الدراسة

يتبين من الجدول السابق لحساب دلالة الفروق بين منوسطات درجات آراء عينة الدراسة

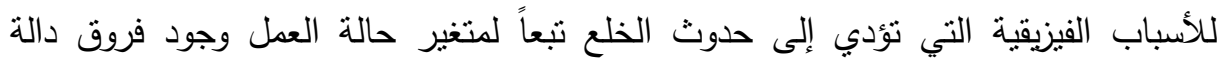

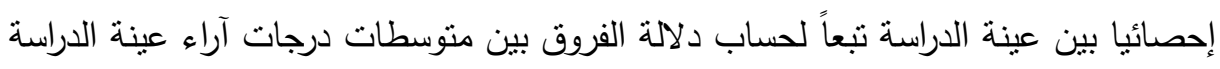

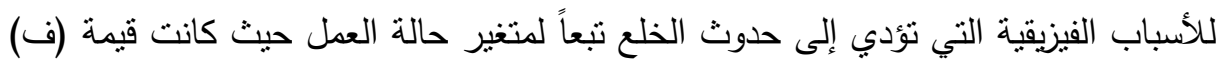

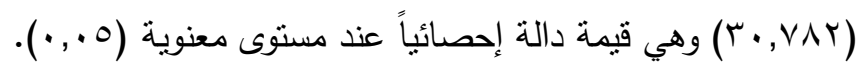

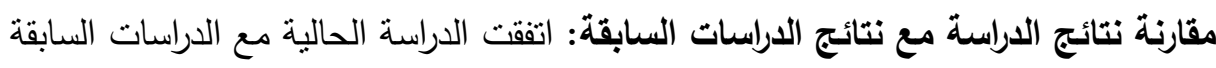

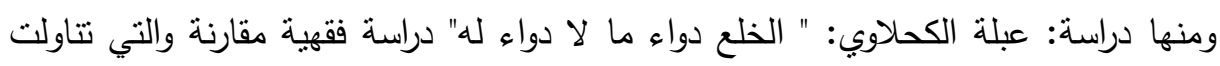

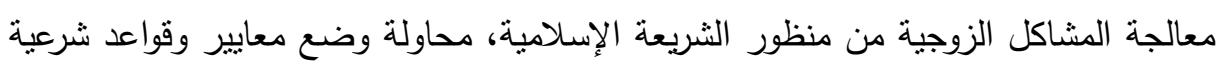

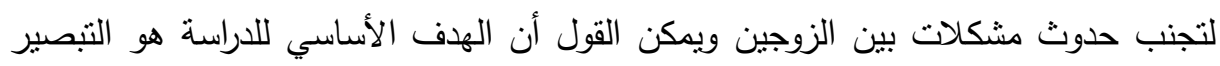
بمعنى الخلع وشروطه، وسبب وجوده في الثريعة الإسلامية . 
كما أكلت دراسة مصطفي الذهبي: الخلع وأحكامه في الثريعة الإسلامية والتي نتاولت قضى التى التها

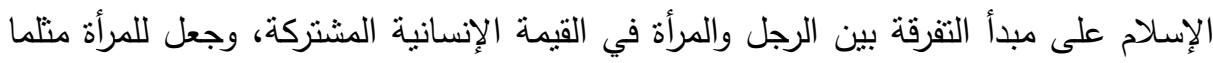

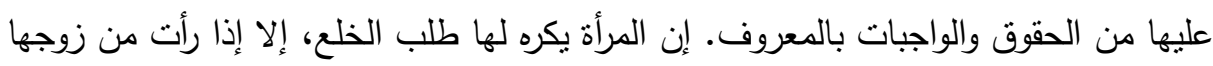

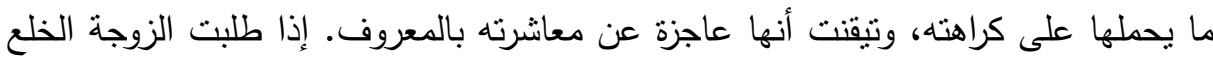

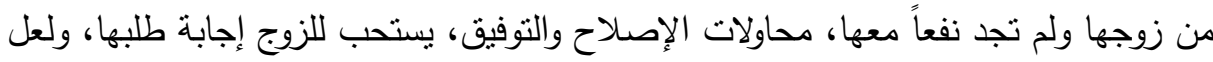

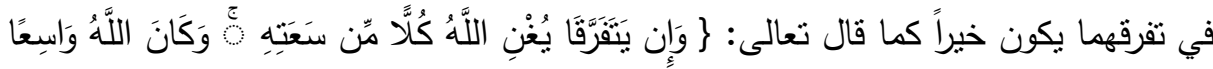

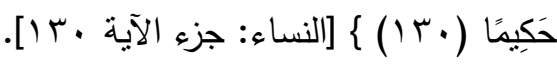
ودراسة أحمد حسام النجار : الخلع ومشكلاته العملية والمنازعات المتعلقة به وإجراءاته العملية وأحكامه والتي أوضحت الدراسة أحكام الخلع، وشروط القضاء بالطلاق خلعاً، ومدى مسئولية

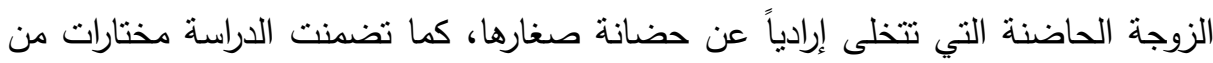

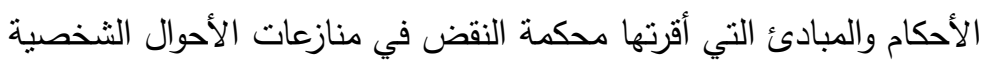

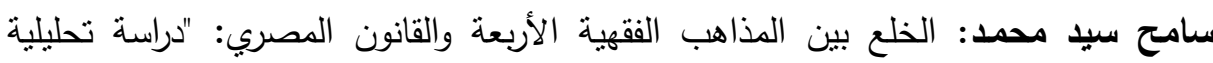

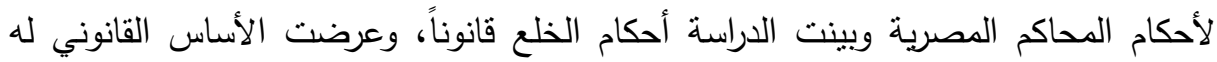

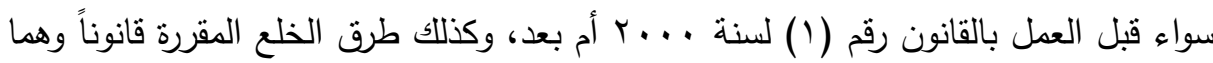
طريقتان: أحدهما اتفاقي وهو الأصل، والآخر قضائي.

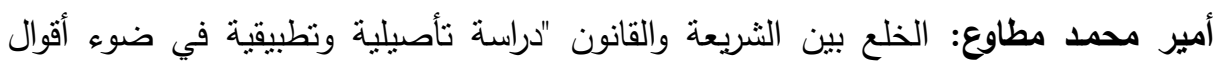
الفقهاء وأحكام القانون واتجاه القضاء ولقد تتاولت الدراسة مكانة المرأة في الإسلام، وقدمت لدان مجموعة من النصائح للأسرة من أجل النهي عن التباغض والأمر بحسن العشرة بين الزوجين

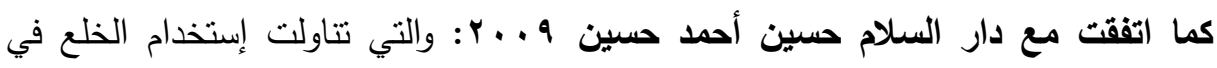

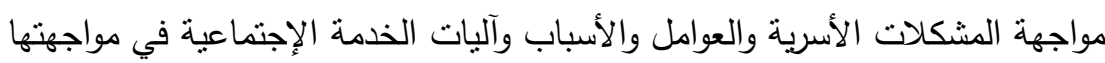
هشام زوين: دعوى الخعع للمسلمين والمسيحيين واليهود طبقاً لقانون إنشاء محاكم الأسرة :

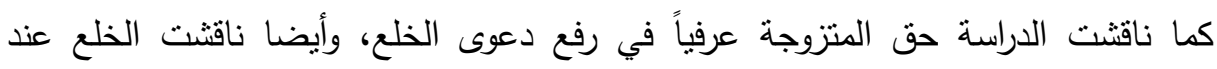
المسيحيين ومدى صلاحية نطبيق نظام الخلع علي المسيحيين، وما هي شروط الحكم للزوجة 
دراسة عدلي السمري . . . ؟ الخلع " دراسة في علم الإجتماع والتي تتاولت أنه كلما ارتفع

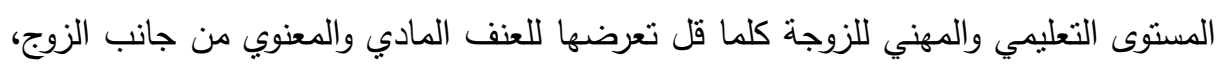

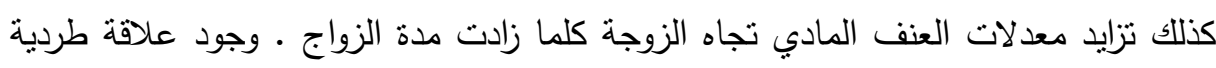

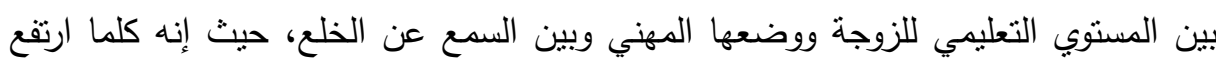

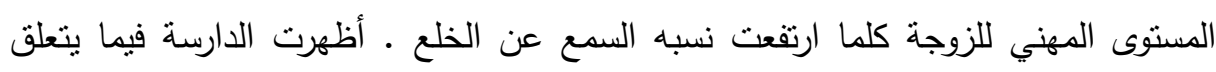

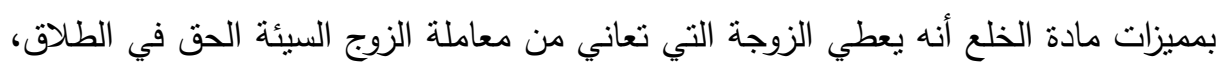

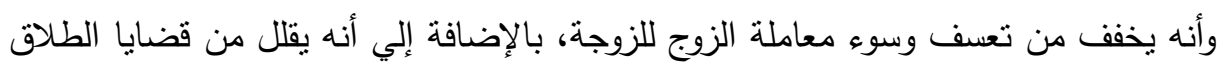

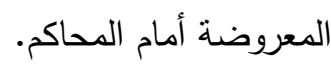

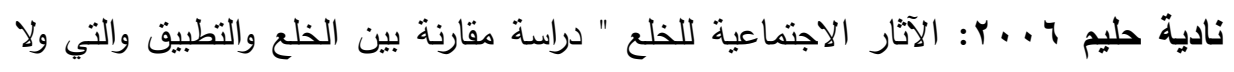

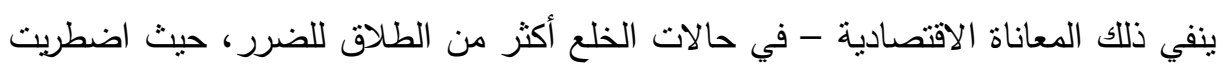

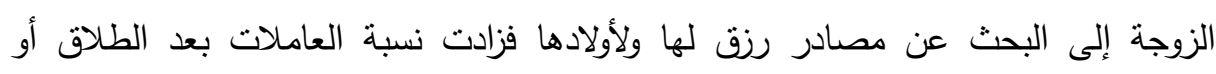

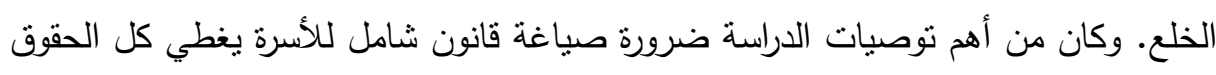

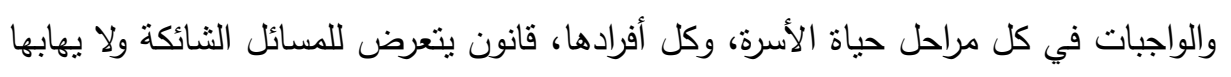

$$
\text { قانون يأني بفكر جديد، ولغة ومفاهيم جديدة عصرية. }
$$

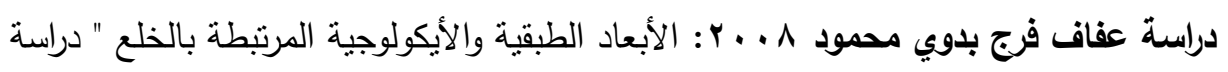

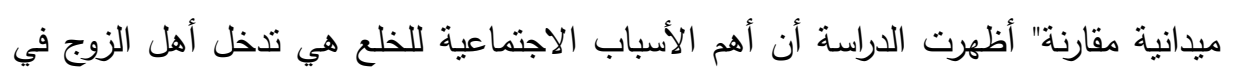

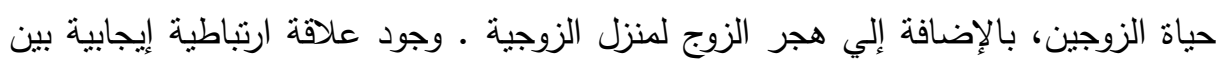

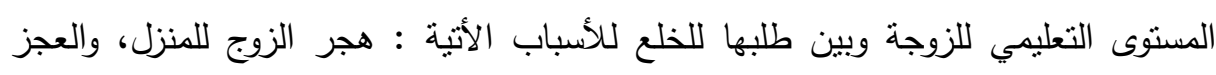

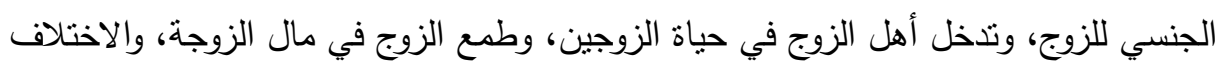

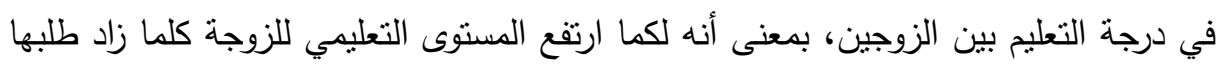
للخلع للأسباب السابقة ـ دراسة Aharon Layish 1995 : الطلاق في الأسرة الليبية. دراسة لئه Francis G.castles الطلاق يؤذي الأطفال. دراسة: Zinsmeister, Karl 2000 : and Michael flood 2002 : السباق الاجتماعي والقانوني للطلاق والتي تتاولت: أوضحت لوند الدراسة أن هناك عوامل اقتصادية طويلة المدى تعتبر أساسية في خلق النزعة المتزايدة نحو 
الطلاق مثل : التحول في الاقتصاد التقليدي للأسرة القائم على الزراعة، والذي كان يخلق نوعاً من الاعتماد المشترك بين الزوجين

\section{zadl}

ابتسام رفعت محمد إدريس: دراسة لبعض المتغيرات الراهنة التي تئدى إلى الطلاق بين

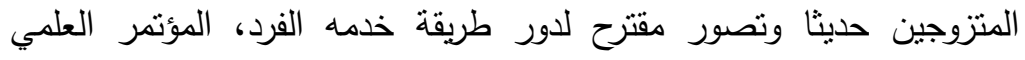

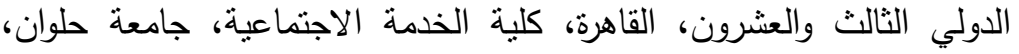

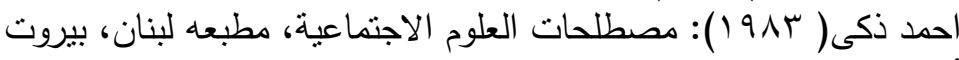

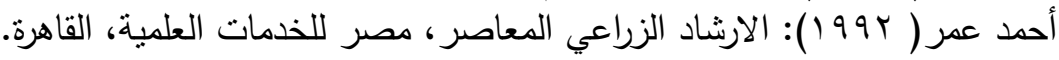

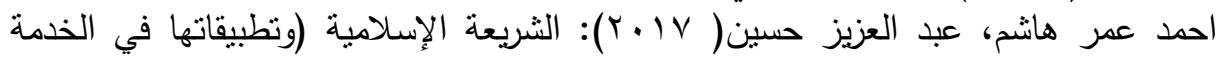

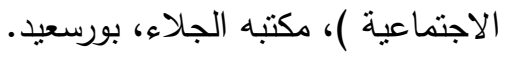

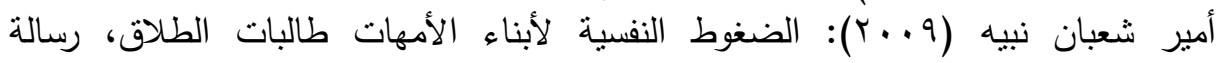

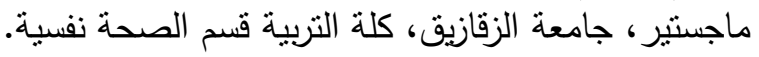

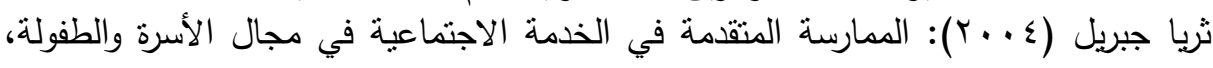

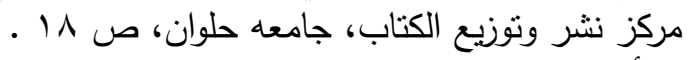

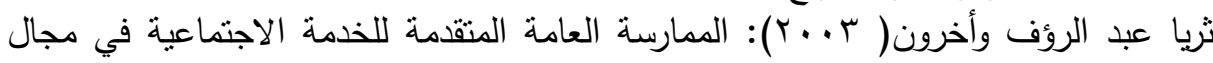

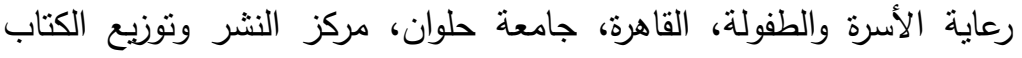

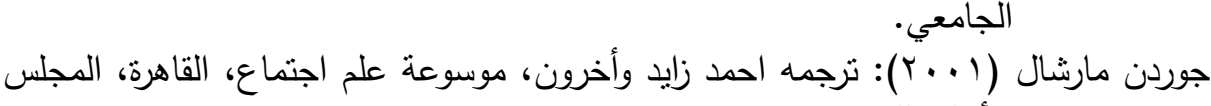
الأعلى للانقافة . ترجمه

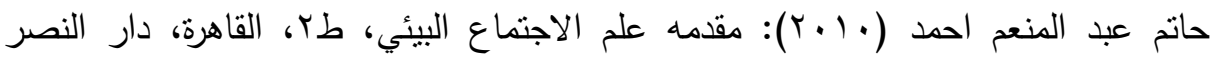

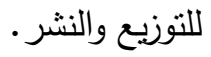

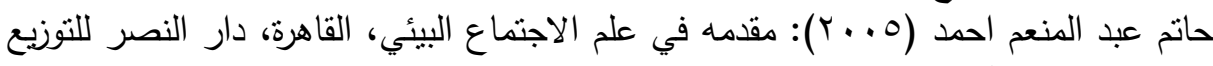

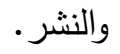

حسان محمد حسن : موسوعة علم الاجتماع - الدار العربية للموسوعات، الطبعة الاولى،

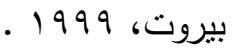

سامية مصطفي الخثاب ( ب99، (199): النظرية الاجتماعية ودراسة الأسرة، القاهرة، دار

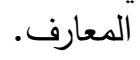

سناء الخولى( r . . r) : الأسرة والحياة العائلية، الاسكندرية، دار المعرفة الجامعية. 


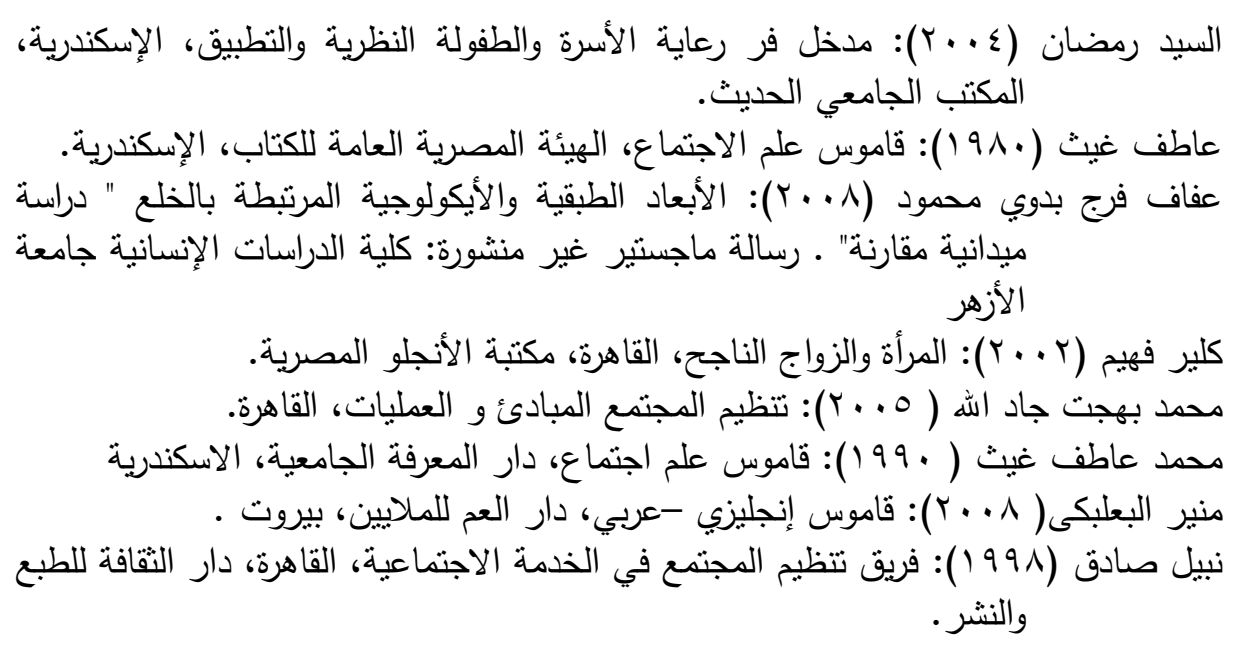

New Webster,s Dictiomary and the saurus, P.I M

\title{
THE SOCIAL AND PHYSICAL VARIABLES ASSOCIATED WITH DIVORCE (TAKING OFF) \\ CAUSEA - CASE STUDY IN PORT SAID GOVERNORATE
}

Shahenda Gharib. ${ }^{(1)}$; Samia S. Khedr. ${ }^{(2)}$ and Eman F. Said..$^{(2)}$

1) Institute of Environmental Studies \& Research, Ain Shams University 2) Faculty of Education, Ain Shams University

\begin{abstract}
Social change is one of the social phenomena that have passed through all human societies. In general, the human society in general and Egyptian society in particular have undergone many changes to their present form. The case of Khula 'is one of the important issues in the current period in society, where it has been increasing continuously, it was necessary to study this issue and know its causes and work on the
\end{abstract}


existence of some solutions to this phenomenon and reduce their impact on society. Therefore, the present study seeks to identify the social and physical variables associated with the issue Khula 'and uncover the relationship between them and reach the best results or preventive measures to reduce the problem of khula that threatens society.

The importance of the study in dealing with a subject that suffers from the society in recent times is the social and physical variables associated with the issue of Khula '. The researchers used the analytical descriptive approach. The study sample consisted of (213) individual. The study reached a number of results, including but not limited to differences There is a statistically significant difference between the study sample and the social variables that lead to the occurrence of khul 'according to the gender variable. There are statistically significant differences between the sample of the study for the physical and psychological reasons that lead to the occurrence of khul' according to the gender variable. To Veziqih and psychological that lead to a dislocation depending on the variable place of residence.

\section{Recommendations:}

- Conducting seminars and lectures in family centers and childhood in the rehabilitation of applicants for marriage.

-The need to link educational curricula to reality and attention to teach students rights and duties of marriage in a proper manner taught by specialists in the field of family, especially in post-primary education.

-It is necessary to activate the places of worship to teach couples the rights and duties of marriage from the book and the Sunnah of the Prophet, and appeal to them to fear God in their wives and children.

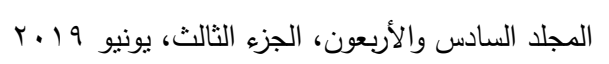

